This document is the accepted manuscript version of the following article:

Maluk, C., Terrasi, G. P., Bisby, L., Stutz, A., \& Hugi, E. (2015). Fire resistance tests on thin CFRP prestressed concrete slabs. Construction and Building Materials, 101, 558-571. https://doi.org/10.1016/j.conbui 1dmat.2015.10.031

This manuscript version is made available under the CC-BY-NC-ND 4.0 1icense http:// creativecommons.org/1icenses/by-nc-nd/4.0/

\title{
1 Fire Resistance Tests on Thin CFRP Prestressed Concrete Slabs
}

2 Cristian Maluk ${ }^{1, *}$, Giovanni Pietro Terrasi ${ }^{2}$, Luke Bisby $^{1}$, Alex Stutz $^{2}$, Erich Hugi ${ }^{2}$

$3 \quad{ }^{1}$ School of Engineering, The University of Edinburgh, UK

$4 \quad{ }^{2}$ Empa, Swiss Federal Laboratories for Material Science and Technology, Switzerland

\section{Abstract}

6 Optimized, high-performance concrete elements, prestressed with carbon fibre reinforced 7 polymer (CFRP) tendons offer great potential within the sustainable modern built 8 environment. However, the performance of these elements in fire is not well known and must

9 be better understood for applications where fire resistance is required. Findings from large10 scale fire resistance tests on thin CFRP prestressed concrete slabs are presented and 11 discussed. Results show that explosive spalling in fire results in sudden collapse, and when 12 spalling is avoided failure occurs by loss of anchorage, which is in turn governed by the 13 temperature of the tendons.

\section{Keywords}

15 Carbon fibre reinforced polymer; precast concrete; prestressing; furnace testing; fire 16 resistance; heat-induced concrete spalling; loss of anchorage

\section{${ }^{*}$ Corresponding Author}

Currently at: School of Civil Engineering, The University of Queensland, Australia

Address: School of Civil Engineering, The University of Queensland, Brisbane QLD 4072, Australia Email: c.maluk@uq.edu.au

Tel: +61733653518 
19 Driven by the need for more durable and sustainable concrete structures; careful selection, 20 design, and optimization of concrete mixes and reinforcing materials used are now 21 commonplace in the precast concrete industry. Concrete elements incorporating high22 performance, self-consolidating concrete (HPSCC) and novel reinforcing and prestressing 23 materials, such as carbon fibre reinforced polymer (CFRP) tendons are one such example [1].

24 The application of thin-walled elements as façade beams and columns in building envelopes 25 (see Figure 1) shows the potential of these structural elements to be widely used in the 26 modern built environment.

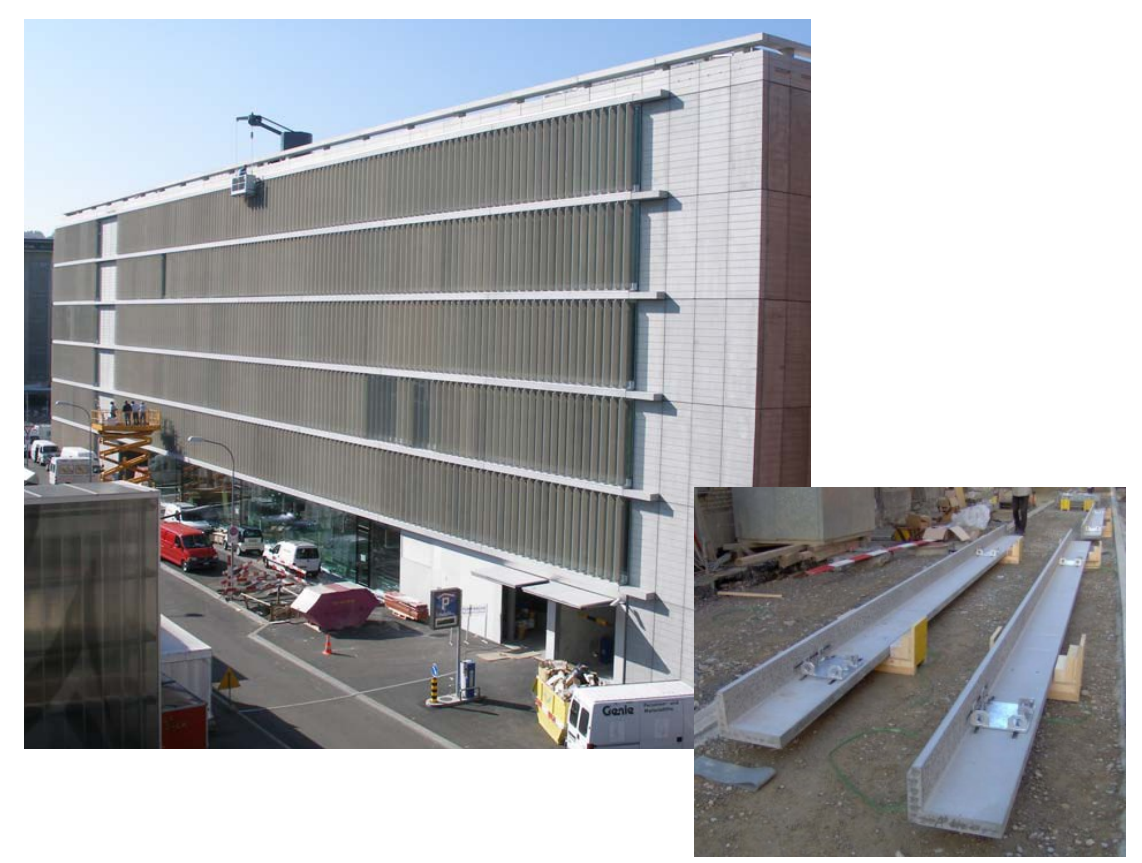

Figure 1 - Application of CFRP prestressed concrete L-shaped beams for structural façade elements in Zurich, Switzerland [1]. 
31 The combined use of CFRP and HPSCC enables the design of optimized, low-weight

32 prestressed elements with a reduced concrete cover and overall thickness [2, 3]; this gives

33 excellent serviceability (corrosion resistance, high stiffness and fatigue strength). However,

34 the performance of these elements in fire is not well known [4] and must be better understood

35 before they can be used with confidence in load-bearing applications where structural fire

36 resistance is required.

37 A limited number of fire resistance tests on fibre reinforced polymer (FRP) reinforced [5, 6, $387,8,9]$ or prestressed [10] concrete elements have been reported in the literature.

39 Unfortunately, however necessarily given the diversity of available FRP reinforcing or 40 prestressing products, each available study has used a specific FRP material, thus making it 41 difficult to draw general conclusions. Despite the scarcity of work studying the fire behaviour 42 of concrete structural elements incorporating FRP reinforcements, fundamental differences to 43 traditionally reinforced concrete structural elements have been reported [10]. Three important 44 failure mechanisms have been identified that may control the fire resistance (i.e. time-to45 failure in a standard fire resistance test) of reinforced or prestressed concrete elements, 46 namely:

47 1. heat-induced explosive concrete spalling;

48 2. thermo-mechanical bond degradation; and

49 3. thermo-mechanically induced longitudinal splitting cracks.

\subsection{Heat-induced concrete spalling}

51 During (or even after) heating in fire, concrete at the exposed surface of structural elements

52 flakes away in a more or less violent manner. This phenomenon is known as 'heat-induced concrete spalling' [11]. As a consequence, the concrete cover to the internal reinforcement 
54 (steel or FRP) is reduced, resulting in rapid temperature increase of the reinforcement and within the structural element, in addition to a direct influence on load bearing capacity due to the loss of physical or effective cross sectional area.

Two main mechanisms are widely considered to contribute to the occurrence of heat-induced concrete spalling. The first is a thermo-hydraulic mechanism associated with the transport and/or evaporation of free water (or capillary water) within the concrete microstructure; this is postulated to lead to generation of steam pressure and a 'moisture clog', and eventually to spalling. It is almost universally agreed that higher moisture content results in increased heatinduced spalling, all other factors being equal [12]. The second is a thermo-mechanical mechanism associated with internal mechanical stresses resulting from through-thickness temperature distributions and incompatibilities in the thermal and thermo-mechanical behaviour of the components within the concrete matrix (e.g. coarse and fine aggregates, cement paste, chemically bound water, etc). This mechanism can also be described at the macro-scale, and linked to internal mechanical stresses resulting from external loading, restraining forces, and/or differential thermal stresses arising due to uneven heating, throughthickness temperature distributions, and/or the presence of cold areas.

The relative significance of these two mechanisms for a particular concrete mix, under a particular thermal exposure in a given application, are not well known. Regardless of the unquantified risk of spalling, current design and construction guidance for spalling prevention (e.g. $[13,14])$ is based on prescribing a dose of polypropylene (PP) fibres which is presumed to assure limited spalling in applications with 'relatively high' spalling risk (e.g. highstrength concrete, high in-service moisture content, high in-service compressive stress, rapidly growing fires, etc). For example, European design guidelines for concrete in fire [13] recommends including at least $2 \mathrm{~kg}$ of monofilament PP fibres per cubic metre concrete for 
high-strength ( $>55 \mathrm{MPa}$ cube compressive strength), high moisture content ( $>3 \%$ by mass) and/or concrete with high inclusion of silica fume ( $>6 \%$ by mass of cement). Australian design guidance for concrete in fire [14] states that the addition of $1.2 \mathrm{~kg}$ of $6 \mathrm{~mm}$ long monofilament PP fibres per cubic metre concrete has a "dramatic effect in reducing the level of spalling”.

\subsection{Thermo-mechanical bond degradation}

Reductions in bond strength between traditional steel reinforcement and concrete are not generally considered to be a governing factor for the fire resistance of steel reinforced or prestressed concrete elements [15]. Conversely, for FRP reinforcements it has been shown that bond strength degradation between FRP tendons and concrete at elevated temperature can be more critical than loss of FRP tensile strength $[8,16]$. Thus, bond strength reduction is widely considered a limiting factor for the fire safe structural design of FRP reinforced and/or prestressed concrete elements [17]. The magnitude of bond strength reductions and their impacts on the performance of FRP reinforced or prestressed concrete structures in fire remain largely unknown, however, and have not been clearly demonstrated for many relevant applications.

The bond between steel or FRP reinforcement (prestressed and/or non-prestressed) and concrete deteriorates at elevated temperature $[17,18,19,20,21]$. These reductions are reasonably well known for steel reinforcement and are given in available guidelines $[13,15]$; however they remain largely unknown for virtually all currently available FRP reinforcements $[22,23]$.

Design codes for the design of FRP reinforced or prestressed concrete structures typically assume perfect bond between FRP reinforcement and concrete for ambient temperature 
101 analysis and design (e.g. [24, 25, 26]. The bond strength of FRP reinforcements relies

102 primarily on the strength and stiffness of the epoxy resin at the surface of the reinforcement,

103 which normally incorporates a sand coating, spiral fibre roving, and/or a ribbed shaped resin.

104 However, the resin at the surface of the FRP tendon will soften at temperatures below $200^{\circ} \mathrm{C}$

105 for most available products [4]; hence the assumption of perfect bond at elevated temperature

106 is not generally appropriate.

\section{$107 \quad 1.3 \quad$ Thermo-mechanically induced longitudinal splitting cracks}

108 FRP reinforcements exhibit vastly different coefficients of thermal expansion (CTEs) in their

109 longitudinal and transverse directions, and these also differ substantially from that of

110 concrete. For example, CFRP reinforcements tend to have lower (even negative) CTEs in the

111 longitudinal direction, while in the transverse direction their CTEs are governed by the matrix

112 polymer [24] and can be up to an order of magnitude larger than for concrete [27]. CTE for

113 FRPs is traditionally examined in the range of temperatures before decomposition of the

114 matrix polymer; $300-350^{\circ} \mathrm{C}[4,27]$.

115 Prior studies have aimed at understanding the effects of differential thermal expansion

116 between FRP reinforcements and concrete [27, 28, 29, 30, 31]. Presently, it is thought that the

117 development of splitting stresses within the concrete cover leads to the development of heat-

118 induced longitudinal (reflective) splitting cracks along the reinforcement, and possibly to loss

119 of the concrete cover's ability to provide sufficient confining action for anchorage to be

120 maintained. It is expected that this may be exacerbated by extreme through-thickness

121 temperature distributions in the concrete during fire [10]. 


\section{RESEARCH SIGNIFICANCE}

124 It is widely perceived that reinforced or prestressed concrete structural elements

125 incorporating FRP reinforcements have lower fire resistance than equivalent steel reinforced

126 or prestressed elements [10]. However, comparatively few large-scale fire resistance tests (or

127 structural fire tests) have been performed on FRP reinforced or prestressed concrete elements;

128 little is known about the 'true' response of these elements during standard fire resistance tests

129 in furnaces. The current paper aims to understand the relative importance of the foregoing

130 issues on fire resistance of FRP prestressed concrete elements using standard fire testing.

\section{EXPERIMENTAL PROGRAM}

132 Five large-scale, loaded CFRP prestressed HPSCC slabs were tested simultaneously in a

133 single standard floor furnace test [32]. The design of the slabs was aimed to evaluate the

134 influence of concrete mix and PP fibre dose (spalling), overall slab depth (tendons

135 temperature), and the presence of CFRP grids within the anchorage zones (splitting cracking

136 in the anchorage zones) (see Table 1).

Table 1 - Evaluated parameters, time-to-failure and failure mechanisms for slabs discussed herein.

\begin{tabular}{lllllllll}
\hline \hline $\begin{array}{l}\text { Slab } \\
\#\end{array}$ & $\begin{array}{l}\text { Concrete } \\
\text { mix }\end{array}$ & $\begin{array}{l}\text { Depth of } \\
\text { the slab } \\
{[\mathbf{m m}]}\end{array}$ & $\begin{array}{l}\text { CFRP } \\
\text { grids }\end{array}$ & $\begin{array}{l}\text { Applied } \\
\text { load per } \\
\text { point } \\
{[\mathbf{k g}]}\end{array}$ & $\begin{array}{l}\text { Slab } \\
\text { utilization } \\
\text { factor }\end{array}$ & $\begin{array}{l}\text { CFRP } \\
\text { utilization } \\
\text { factor }\end{array}$ & $\begin{array}{l}\text { Time-to- } \\
\text { failure } \\
\text { [mm' ss"'] }\end{array}$ & Failure mechanism \\
\hline \hline 1 & $\mathrm{~A}$ & 45 & No & 25.0 & 0.23 & 0.42 & $42^{\prime} 01^{\prime \prime}$ & Loss of anchorage \\
2 & $\mathrm{~A}$ & 45 & Yes & 25.0 & 0.23 & 0.42 & $12^{\prime} 37^{\prime \prime}$ & Explosive spalling \\
3 & $\mathrm{~A}$ & 60 & Yes & 38.4 & 0.20 & 0.43 & $22^{\prime} 10^{\prime \prime}$ & Explosive spalling \\
4 & $\mathrm{~B}$ & 45 & Yes & 25.0 & 0.23 & 0.42 & $50^{\prime} 27^{\prime \prime}$ & Loss of anchorage \\
5 & $\mathrm{~B}$ & 60 & Yes & 38.4 & 0.20 & 0.43 & $93^{\prime} 04^{\prime \prime}$ & Loss of anchorage \\
\hline \hline
\end{tabular}




\subsection{Test specimens}

139 The tested slabs were similar to those used by the authors in prior research [10]. Their overall

140 length was $3360 \mathrm{~mm}$ (see Figure 2) and they were prestressed with four circular pultruded,

141 quartz sand-coated CFRP tendons stressed to an initial prestress level of 1,000 MPa. Initial

142 prestress level was calculated based on the gross cross-sectional area of the tendons; i.e

143 without considering the layer of sand coating (refer to Section 3.2.2 of this paper). It is

144 noteworthy to point out that for prestressed concrete elements, the ends the slabs are

145 commonly labelled as active end (stressing end) and passive end (dead end).

146 All CFRP tendons were located at the slab mid-depth, with a tolerance of $\pm 2 \mathrm{~mm}$, to obtain a

147 nominally concentric prestressing force (see Figure 3). The slabs were 45 or $60 \mathrm{~mm}$ thick

148 (refer to Table 1), leading to clear concrete covers to the prestressed CFRP reinforcement of

$14919.5 \mathrm{~mm}$ and $27 \mathrm{~mm}$, respectively. All slabs were $200 \mathrm{~mm}$ wide. Lateral clear concrete cover

150 at the slab edges was $22 \mathrm{~mm}$ in all cases, with a tendon-to-tendon clear spacing of $44 \mathrm{~mm}$

151 (see Figure 3). 
Plan view

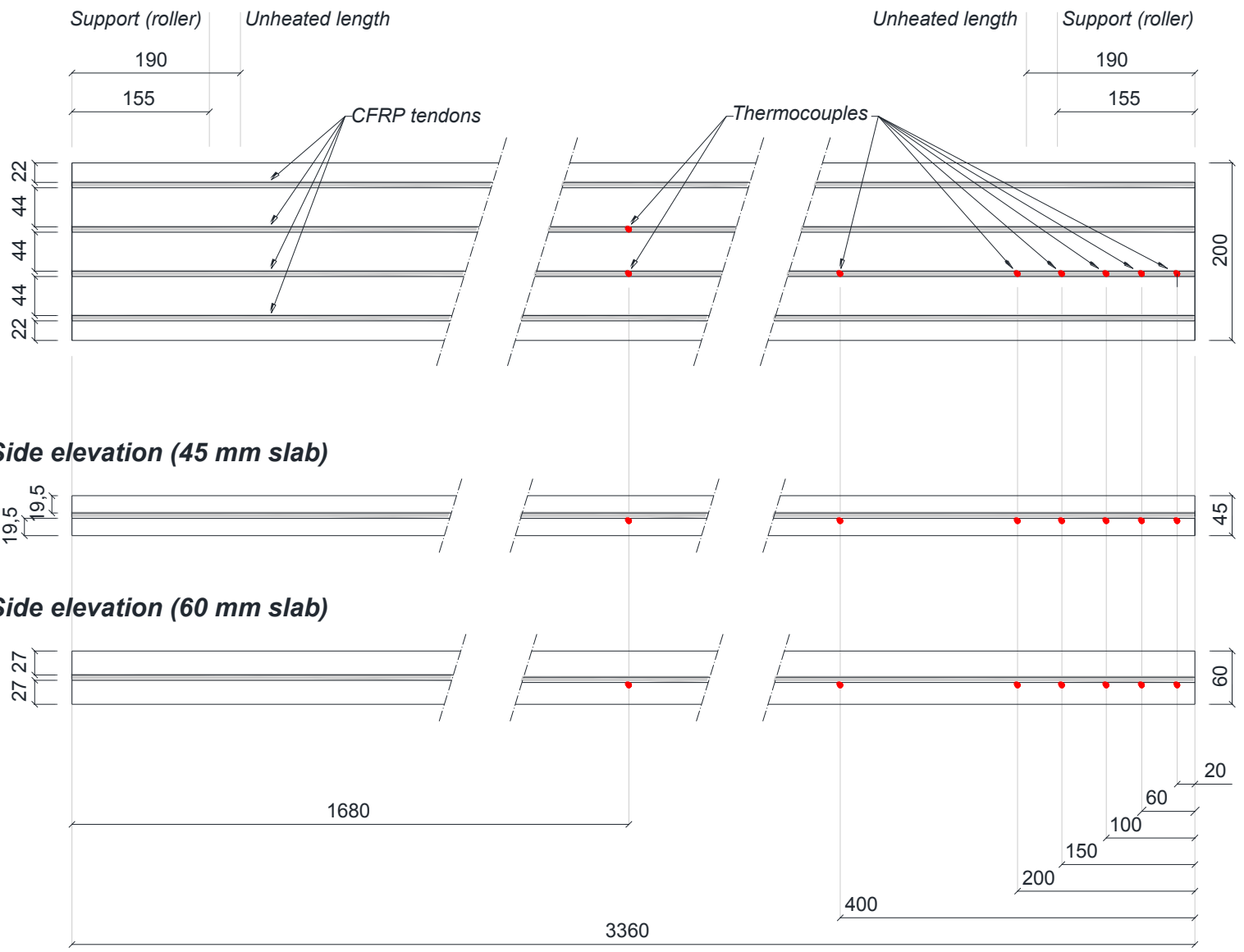
position (CFRP grids in the anchorage zones are not shown).

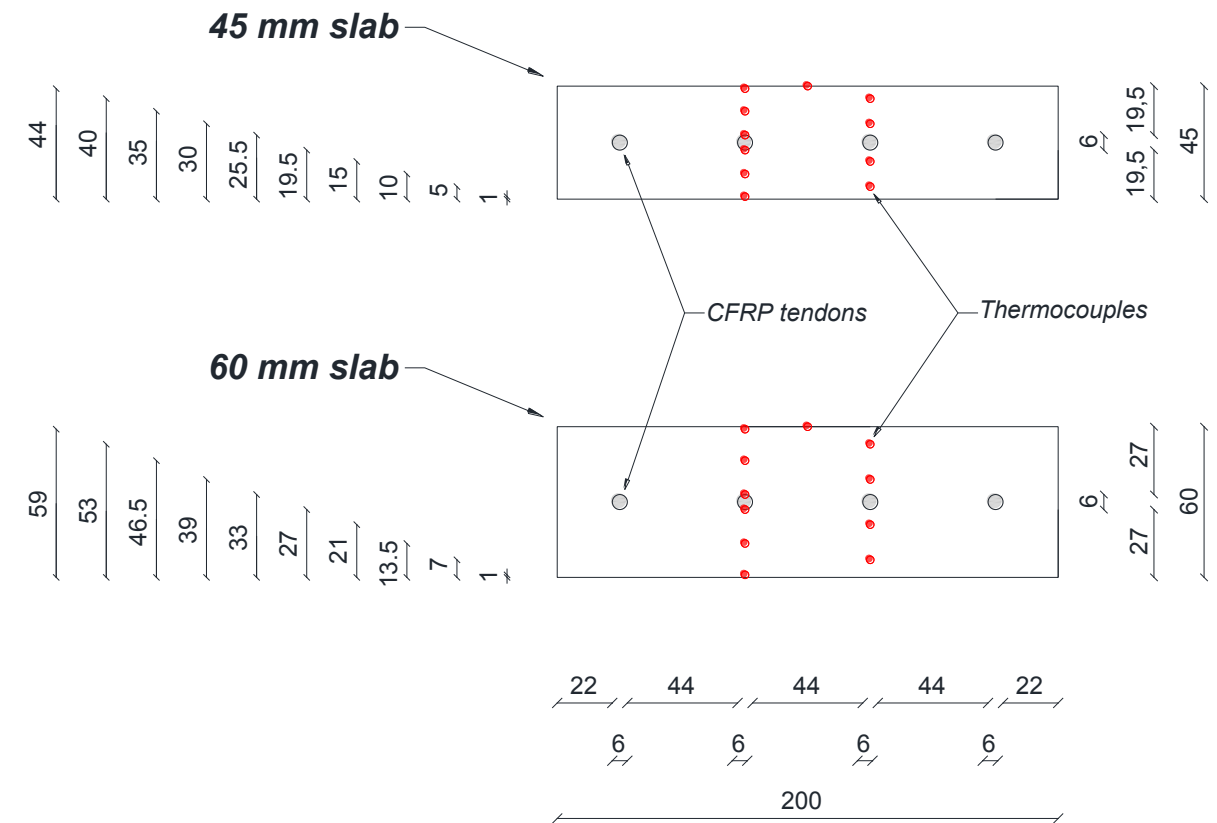

Figure 3 - Cross section for slabs 45 and $60 \mathrm{~mm}$ thick, also showing thermocouples position. 
160 All slabs were fabricated from a high-performance, self-consolidating concrete (HPSCC) of 161 strength class C90 (minimum 28 day $150 \mathrm{~mm}$ cube compressive strength of $90 \mathrm{MPa}$ ). Given

162 the high likelihood of spalling for this mix due to its high strength and the inclusion of 163 microsilica in the mix [13], $2.0 \mathrm{~kg}$ of $3 \mathrm{~mm}$ long or $1.2 \mathrm{~kg}$ of $6 \mathrm{~mm}$ long PP monofilament

164 fibres (32 $\mu \mathrm{m}$ in diameter) were included for mixes A and B, respectively. Detailed of both 165 mixes are given in Table 2.

166 Moisture content was measured by dehydration mass loss of control specimens. The average

167 moisture contents at the time of testing were 3.6 and $3.9 \%$ by mass, for mixes $\mathrm{A}$ and $\mathrm{B}$, 168 respectively. Compressive and splitting tensile strengths [33] were measured at 28 days and 6 169 months (close to the time of testing), and are given in Table 2.

170 of testing), and are given in Table 2.

Table 2 - Mix composition and slump flow for the HPSCC mixes.

\begin{tabular}{|c|c|c|c|}
\hline & & Mix \#A & Mix \#B \\
\hline $\begin{array}{l}\text { Water/(cement }+ \text { microsilica }+ \text { fly } \\
\text { ash) }\end{array}$ & {$[-]$} & 0.31 & 0.31 \\
\hline Cement (includes $20 \%$ microsilica) & {$\left[\mathrm{kg} / \mathrm{m}^{3}\right]$} & 475 & 469 \\
\hline Fly ash & {$\left[\mathrm{kg} / \mathrm{m}^{3}\right]$} & 120 & 120 \\
\hline Limestone aggregate $(0-8 \mathrm{~mm})$ & {$\left[\mathrm{kg} / \mathrm{m}^{3}\right]$} & 1675 & 1669 \\
\hline Superplasticizer in $\%$ of cement & {$[\%]$} & $1.69 \%$ & $1.75 \%$ \\
\hline Polypropylene fibres & {$\left[\mathrm{kg} / \mathrm{m}^{3}\right]$} & $\begin{array}{r}2.0 \\
(3 \mathrm{~mm} \text { PPs })\end{array}$ & $\begin{array}{r}1.2 \\
(6 \mathrm{~mm} \text { PPs })\end{array}$ \\
\hline Slump flow [34] & {$[\mathrm{mm}]$} & 830 & 785 \\
\hline $\begin{array}{l}\text { Compressive strength ( } 28 \text { days / } 6 \\
\text { months) }\end{array}$ & {$[\mathrm{MPa}]$} & 92.6 / 93.3 & $96.2 / 98.5$ \\
\hline $\begin{array}{l}\text { Splitting tensile strength ( } 28 \text { days / } 6 \\
\text { months) }\end{array}$ & {$[\mathrm{MPa}]$} & $5.44 / 5.47$ & $5.49 / 5.57$ \\
\hline $\begin{array}{l}\text { Moisture content (at the time of } \\
\text { testing) }\end{array}$ & $\begin{array}{l}{[\% \text { by }} \\
\text { mass }]\end{array}$ & $3.6 \%$ & $3.9 \%$ \\
\hline
\end{tabular}


174 The pultruded uniaxial CFRP tendons used herein were made from Tenax UTS carbon fibres, at a fibre volume fraction of $64 \%$, and Bakelite 4434 epoxy resin. Their design tensile strength was 2,000 $\mathrm{MPa}$, with a design elastic modulus of $150 \mathrm{GPa}$ [35] and a characteristic ultimate strain of $1.33 \%$. The quartz sand coating applied after the initial pultrusion process

178 had an average grain size of $0.5 \mathrm{~mm}$ and was bonded using the same epoxy resin to promote a

179 strong bond. The gross (or net) diameter of the CFRP tendons was $5.4 \mathrm{~mm}$ and the total 180 diameter, including sand coating, was approximately $6.0 \mathrm{~mm}$ (see Figure 4).

181

182

183

184

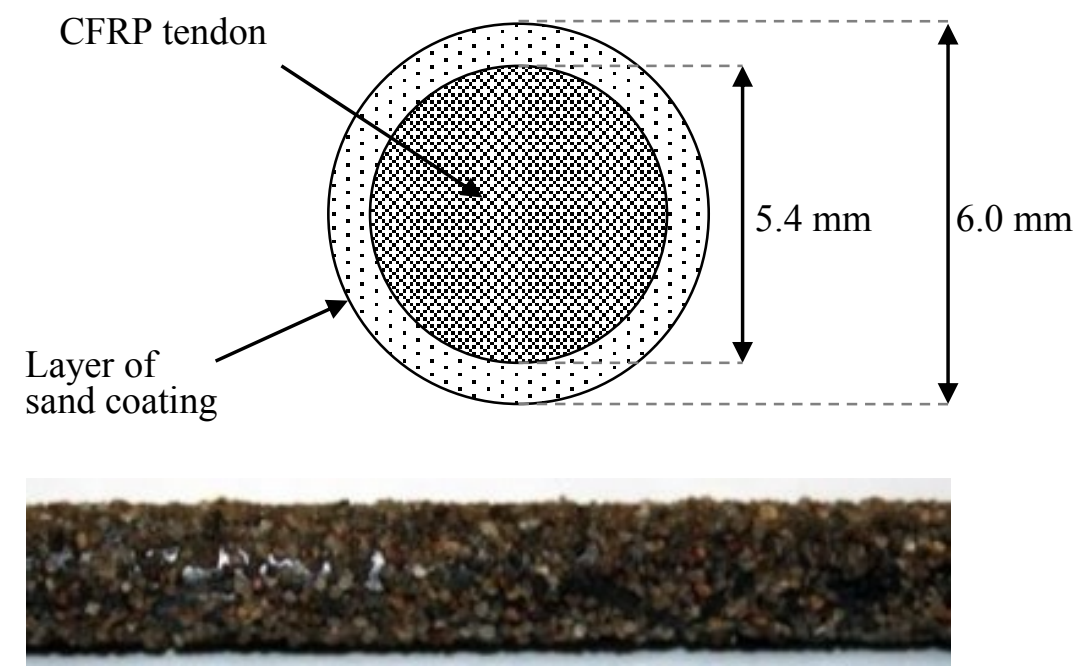

Figure 4 - Cross section schematic and photo of the CFRP prestressing tendon used in the current study.

\subsubsection{CFRP grid reinforcement}

In an attempt to limit splitting cracking and improve the bond strength in the prestress anchorage zones at elevated temperatures, commercially available CFRP grids (C-GRID ${ }^{\circledR}$ ) were placed locally within the anchorage zones of four of the five slabs (refer to Table 1). Prior to casting, these CFRP grids were placed above and below the CFRP tendons (see Figure 5). The aim was to minimize heat-induced longitudinal splitting cracks, and hence loss of confining action provided by concrete in the anchorage zones. The CFRP grids had 


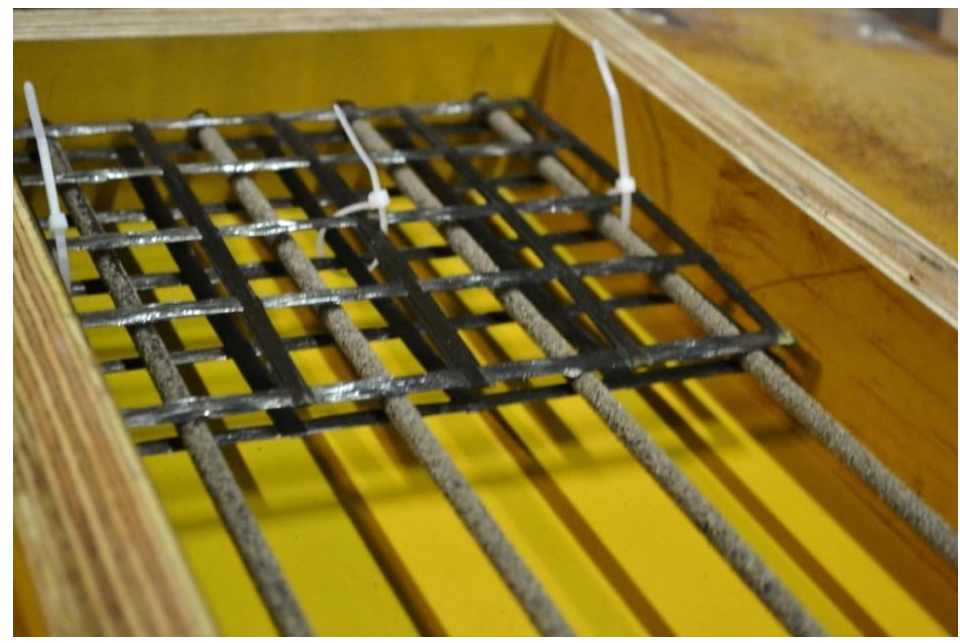

Figure 5 - Placement of CFRP grids within the anchorage zones (above and below the CFRP tendons).

\subsection{Casting and curing procedures}

The formwork (i.e. prestressing bed) allowed for simultaneous casting of three prestressed slabs at one time (see Figure 6). The mixing and casting procedure was performed according

197 the exacting standards for typical precast concrete elements fabricated by the industrial partner (a Swiss precast company). After casting, slabs were covered with polyethylene sheeting for 72 hours before the prestress was transferred and the forms stripped. The slabs were cured in a moist condition under polyethylene sheets for a further five days, and were then left to cure under ambient conditions for 1.5 months in the production hall of the precast company before being delivered to the Empa Fire Testing Laboratory where they were stored indoors until testing. Slabs were tested at an age of 5.2 months (testing authorities typically prescribe a minimum age of 3 months for furnace testing of concrete [32]). Cube and cylinder specimens were also cast to determine compressive and splitting tensile strength, as well as average moisture content at the time of testing. 

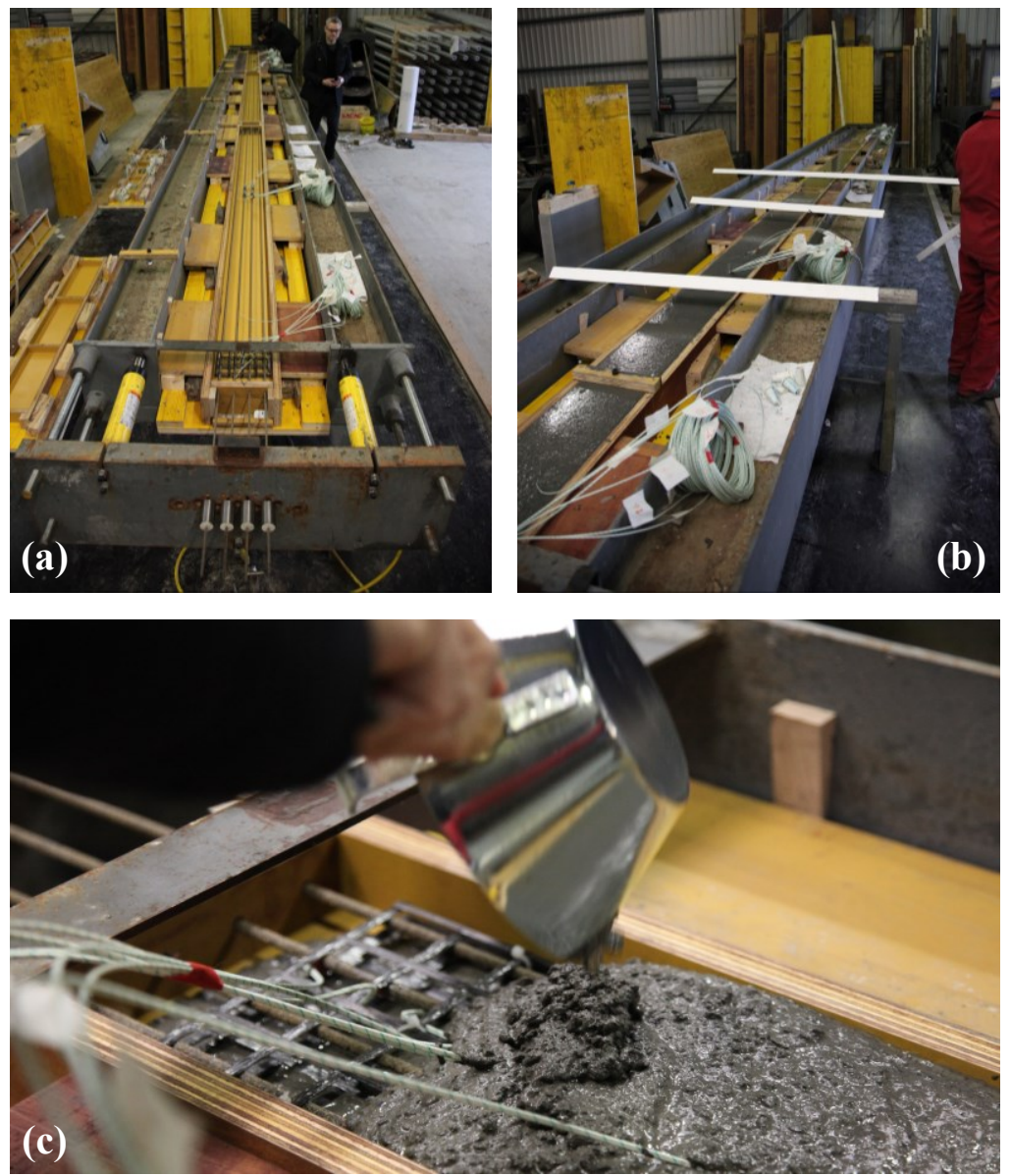

Figure 6 - Photographic sequence showing (a) prestressing bed and formwork prior to casting, (b) casting procedure of large-scale specimens, and (c) close-up during casting of the anchorage zone (with CFRP grids and thermocouples). 


\section{LARGE-SCALE FURNACE TEST}

214 A large-scale furnace test (standard fire resistance test) was performed at Empa's Fire Testing

215 Laboratory in Dubendorf, Switzerland. The five specimens described previously were

216 simultaneously loaded and exposed to a standard fire (see Figure 7) using a floor furnace

217 [32].

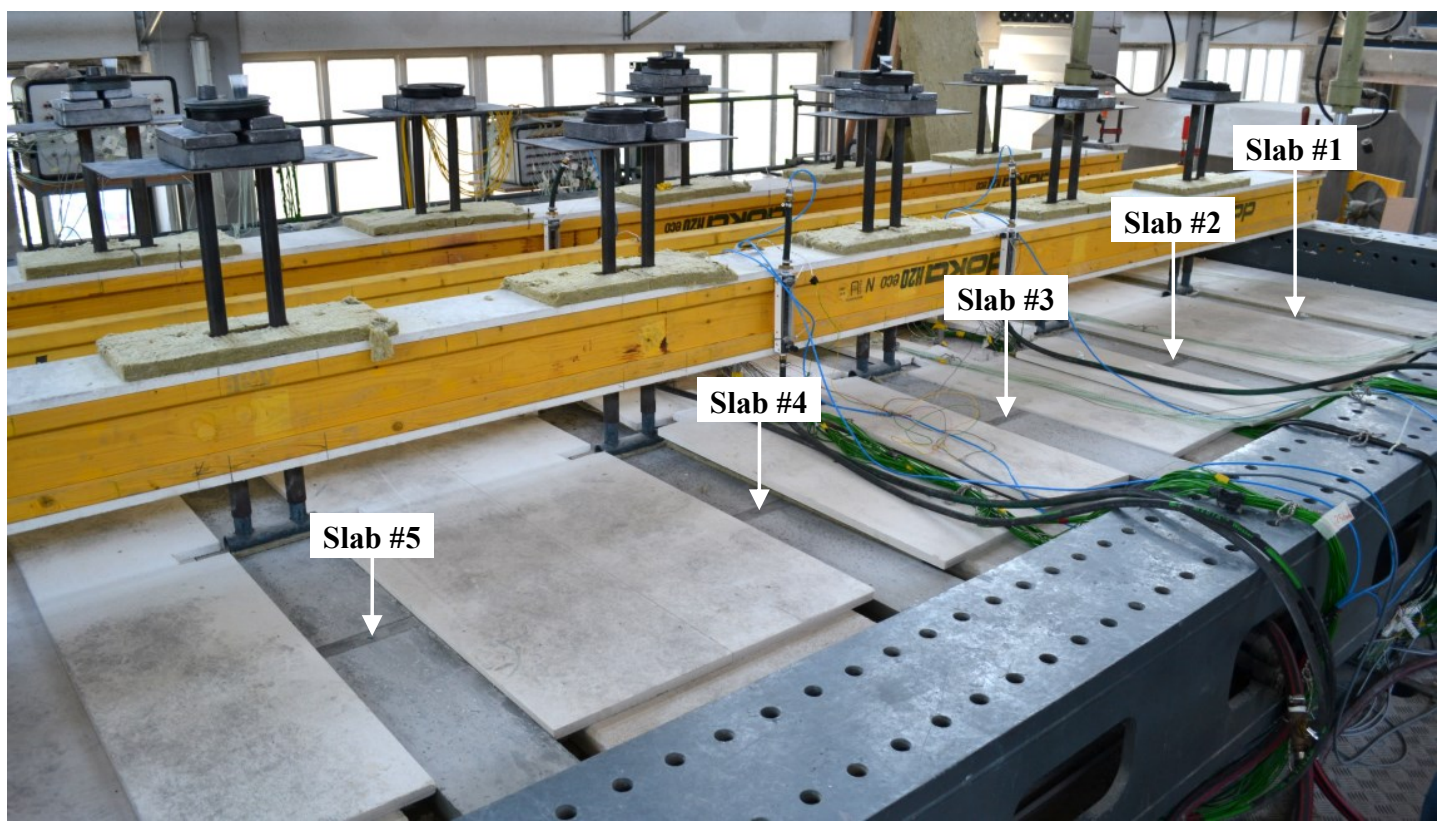

$219 \quad$ Figure 7 - Photo of the fire resistance test setup showing positions of the respective slabs and sustained 
223 The test was performed in accordance to the European requirements of the standard fire 224 resistance test [32].

\subsubsection{Thermal loading}

226 The setup of the specimens was aimed at assuring one-sided heating from below, so the sides

227 of the specimens were fully insulated. The heating regime was executed according to the 228 requirements of the standard time-temperature curve [32]. Since no clear influence of an 229 unheated anchorage length in excess of $160 \mathrm{~mm}$ had been observed during a prior series of 230 furnace tests performed by the authors [10], it was decided to maintain a constant but 231 conservative (and essentially arbitrary) unheated anchorage length of $195 \mathrm{~mm}$ for all five 232 specimens (refer to Figure 2). Thus, the overall exposed length of the $3360 \mathrm{~mm}$ long slabs 233 was $2970 \mathrm{~mm}$.

\subsubsection{Mechanical loading}

235 Sustained mechanical loading was applied to simulate an in-service condition for the slabs, in

236 simply-supported four-point bending. End supports (rollers) were placed $155 \mathrm{~mm}$ from the

237 slabs' ends, leading to a structural span of $3050 \mathrm{~mm}$ (see figures 8 and 9). The applied load

238 was designed to be sufficient to achieve decompression at the extreme tension fibre within

239 the constant moment region (i.e. $\sigma_{c, \text { botom }}=0[\mathrm{MPa}]$ ); this corresponds to a typical design service

240 load condition for a façade element of this type in a real building [1]. Loading was imposed

24130 minutes prior to start of heating. 
242 Prestressing losses due to elastic shortening, shrinkage and creep of the concrete were

243 considered and calculated based on results from prior experimental studies performed for

244 similar HPSCC mixes [36]. Total prestressing losses $\left(\Delta \sigma_{p}^{\text {Total }}\right)$ were calculated as:

$245 \Delta \sigma_{p}^{\text {Total }}=\Delta \sigma_{p}^{E S}+\Delta \sigma_{p}^{S R}+\Delta \sigma_{p}^{C R}$

246 Losses due to elastic shortening of concrete were calculated as:

$247 \Delta \sigma_{p}^{E S}=\frac{E_{C F R P}}{E_{c}} \cdot \sigma_{c, 0}$

248 where:

$249 \quad \sigma_{c, 0}=\sigma_{C F R P, 0} \cdot \frac{A_{C F R P}}{A_{c}-A_{C F R P}}$

$250 \quad E_{c}=32.5[\mathrm{GPa}]$

(at 2-3 days) [36]

$251 \quad E_{\text {CFRP }}=150[\mathrm{GPa}]$

252 Losses due to shrinkage of concrete were calculated as:

$253 \Delta \sigma_{p}^{S R}=E_{C F R P} \cdot\left(-\varepsilon_{c}^{S R}\right)$

254 Concrete strains due to shrinkage $\left(\varepsilon_{c}^{S R}\right)$ at the time of testing were calculated by interpolating 255 between measurements on HPSCC control specimens at various ages [36]. Losses due to 256 creep of concrete were calculated as:

$257 \Delta \sigma_{p}^{C R}=\varphi_{c} \cdot \frac{E_{C F R P}}{E_{c}} \cdot \sigma_{c, \text { creep }}$

258 where: 
$259 \quad \sigma_{c, \text { creep }}=\varphi_{\text {CFRP }} \cdot\left(\sigma_{\text {CFRP }, 0} \cdot \frac{A_{\text {CFRP }}}{A_{c}-A_{C F R P}}\right)$

260 The concrete creep coefficient $\left(\varphi_{c}\right)$ and bond creep coefficient $\left(\varphi_{C F R P}\right)$ were defined based on

261 results from prior experimental studies performed for similar specimens [36].

262 Finally, initial prestressing level at the time of testing were calculated as:

263

$\sigma_{C F R P, \text { test }}=\sigma_{C F R P, 0}-\Delta \sigma_{p}^{\text {Total }}$

264 and prestress losses could then be calculated as:

265 Prestressing losses $(\%)=\frac{\Delta \sigma_{p}^{\text {Total }}}{\sigma_{\text {CFRP }, 0}} \times 100$

266 Prestressing losses for 5.2 month old slabs with CFRP tendons initially prestressed to 1,000

$267 \mathrm{MPa}$ were calculated as $16 \%$ and $14 \%$ for the 45 and $60 \mathrm{~mm}$ thick slabs, respectively (refer to

268 Table 1). The slab utilization factors, calculated as the ratio between the applied mechanical

269 load during testing and the theoretical ultimate failure load at ambient temperature, assuming

270 concrete crushing at the compressive zone [11], were 0.23 and 0.20 for the 45 and $60 \mathrm{~mm}$

271 thick slabs, respectively.

272 The CFRP utilization factor was calculated as the ratio between the initial strain of the CFRP

273 tendons during testing (considering losses) and their characteristic ultimate failure strain.

274 Before heating these were 42 and $43 \%$ of the CFRPs' design tensile strength capacity for the 27545 and $60 \mathrm{~mm}$ thick slabs, respectively. 


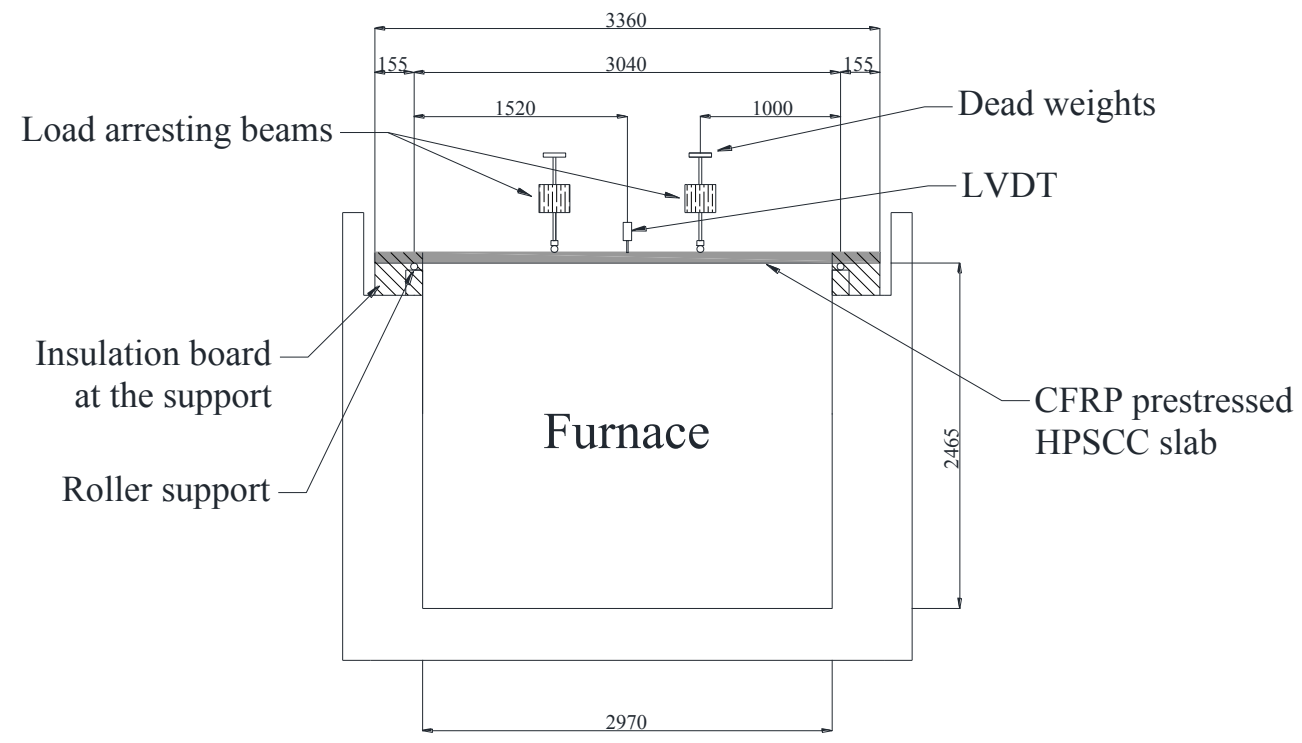

Figure 8 - Test setup, loading, and selected instrumentation for the fire resistance test (side elevation).

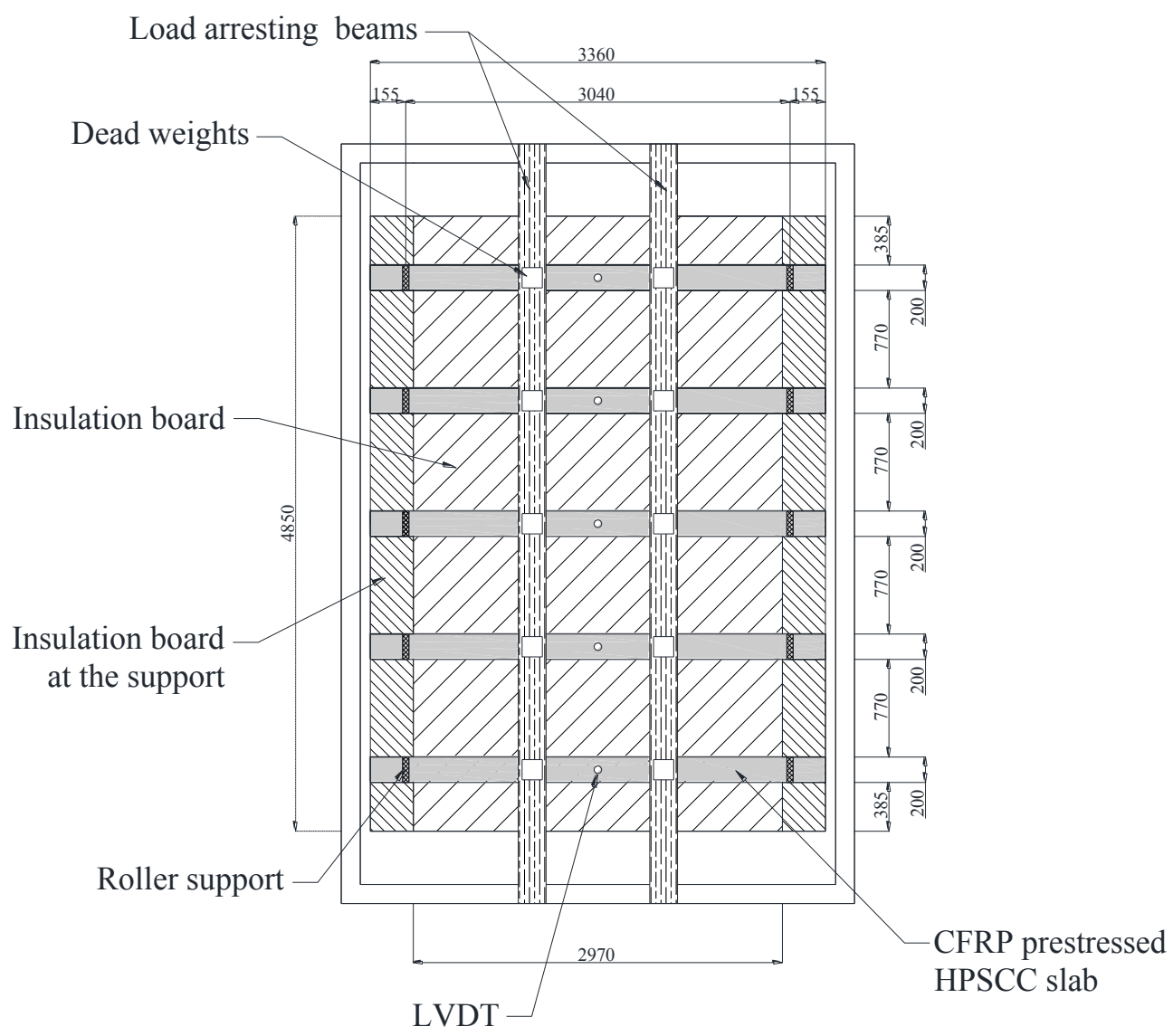

Figure 9 - Layout of test specimens during the fire resistance test (plan view). 


\subsection{Instrumentation}

282

283

284

285

286

287

288

289

290

291

292

293

294

295

296

297

298

299

300

301

302

303

- Furnace temperature gauges - In accordance with fire test standards [32] eight standard plate thermometers were positioned inside the furnace. These were used to record and control the temperatures inside the furnace during testing.

- Temperature gauges inside the slabs - Through-thickness temperature measurements were taken at midspan at eleven distances from the exposed surface of each of the slabs (see Figure 3). Temperature measurements were also taken at several locations in the anchorage zones (active end only) along the lower edge of one central CFRP tendon (see Figure 2). Bare K-type thermocouples (TCs) were used in all cases, and special care was taken during the casting process to ensure precise placement of the TCs at the intended location inside the slabs.

- Midspan vertical displacement gauges - Midspan vertical deflection was measured using linear voltage displacement string pot transducers, placed on a beam resting on top of the furnace.

- Draw-in gauges - Aiming to measure possible draw-in of the CFRP tendons during testing due to loss of anchorage from heating or splitting cracking of the anchorage zones high accuracy yet economical, semi-disposable custom-built "pi" displacement gauges (pi-gauges) were designed and fabricated for the project described herein (one of these gauges is shown in Figure 10). These were placed at either end of the slabs (active and passive ends). These 'pi-gauges' consisted of foil strain gauges applied to a piece of curved spring steel, which when flexed due to deformation could be correlated to displacement. To obtain the required accuracy of the instruments, the gauges were designed with a half-bridge connection with strain gauges placed on the top and bottom 

range of $\pm 4 \mathrm{~mm}$. Draw-in measurements were performed for all four CFRP tendons, at

306 both ends of slabs \#1, \#2, and \#3 (refer to Table 1).

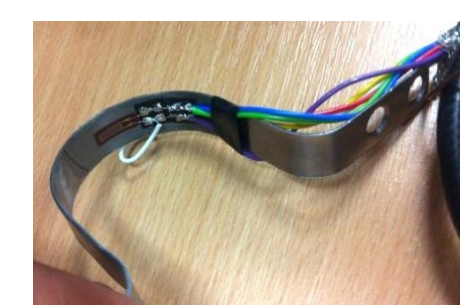

Figure 10 - Custom-fabricated 'pi-gauges' (left) and gauges installed for measuring tendon draw-in for
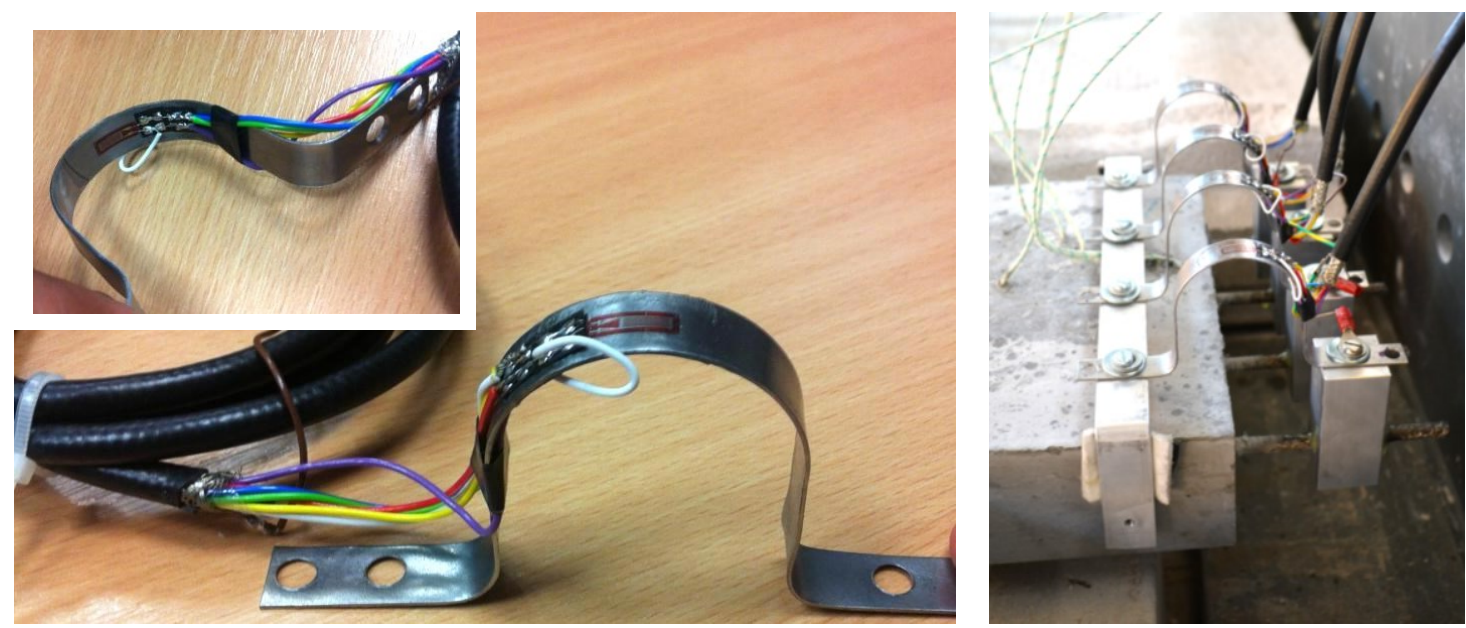
all four tendons at one end of Slab \#1 (right).

\section{TEST RESULTS AND ANALYSIS}

311 The observed time-to-failure of all five test specimens is shown in Table 1, along with their

312 respective failure modes. Failure was driven by either:

313 - a single explosive heat-induced spalling event, which resulted in immediate and total

314 collapse of the test specimen (slabs \#2 and \#3); or

- progressive loss of bond between the tendon and the concrete in the anchorage zone,

316 leading to more gradual collapse of the test specimen (slabs \#1, \#4, and \#5).

\section{$317 \quad 5.1 \quad$ Furnace temperature}

318 Temperature measurements from the eight plate thermometers inside the furnace are shown

319 in Figure 11 along with the objective time-temperature curve. Although compliant with the 
320 testing standard [32], the temperature measurements show substantial deviation in the

321 temperature measured inside the furnace, especially during the first 20 minutes (see Figure

322 12). Due to the obvious technical challenge of precisely controlling the furnace to follow the 323 rapidly growing prescribed time-temperature curve [32] during early stages of the test, most 324 testing standards do not prescribe an allowable deviation during the first 5 minutes (see 325 Figure 12).

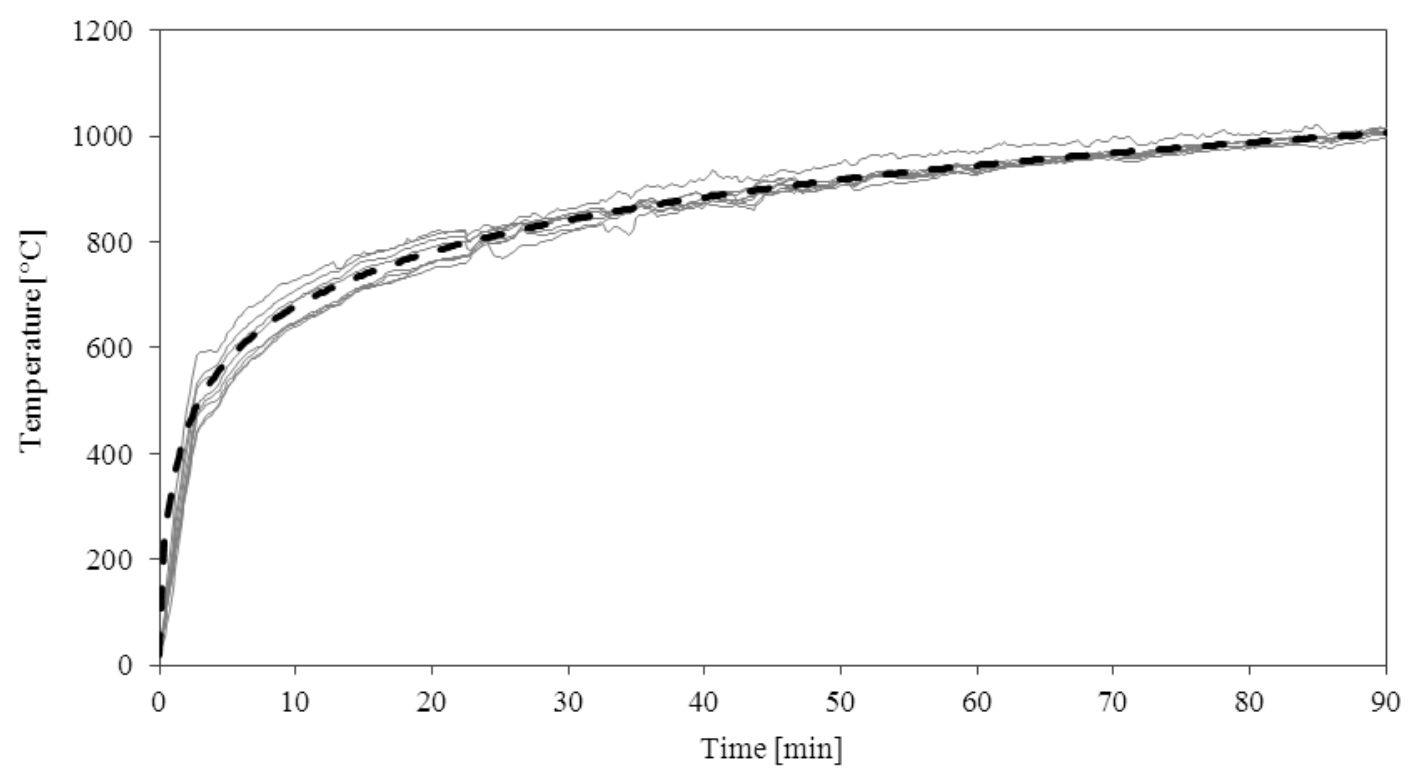

Figure 11 - Furnace gas temperatures measured by the plate thermometers along with the objective standard time-temperature curve [32].

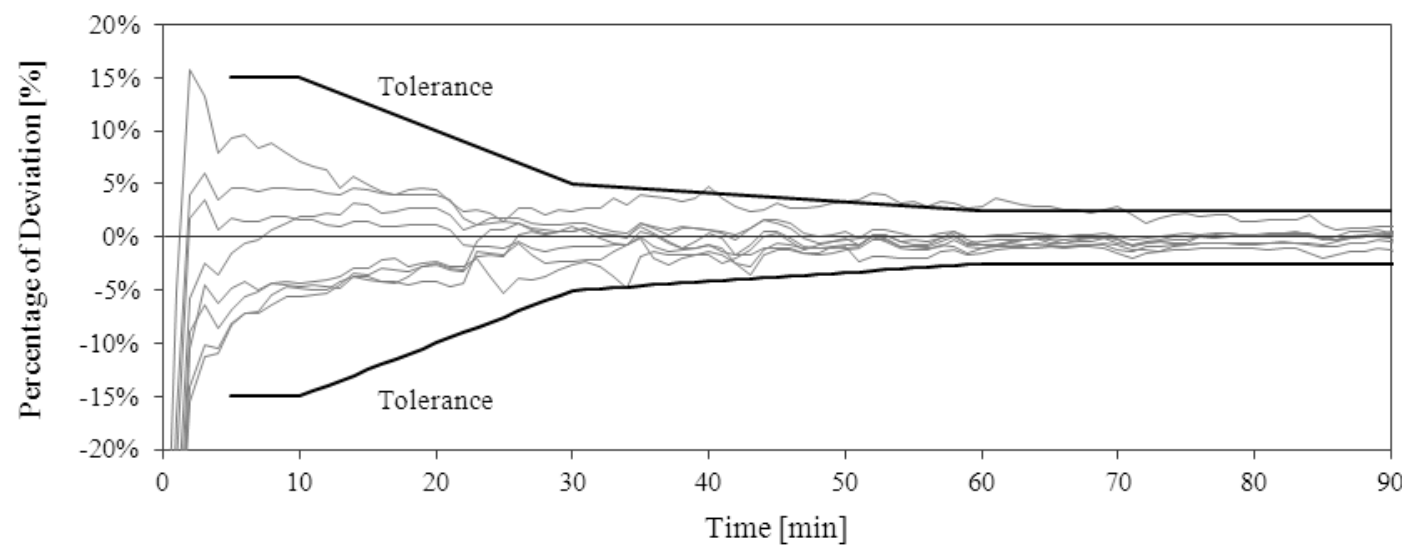

Figure 12 - Percentage of deviation of the temperature measured by plate thermometers from that of the objective temperature, and the maximum allowable deviation (tolerance) [32]. 


\subsection{Through-thickness temperatures at midspan}

334 A comparison of through-thickness temperature distributions measured at midspan is shown

335 in figures 13 and 14 for slabs 45 and $60 \mathrm{~mm}$ thick, respectively. Temperature for the first 12

336 minutes of the test are shown; the time at which the first of the slabs failed due to explosive

337 spalling (refer to Table 1).

338 Considerable variation of through-thickness temperature distributions was observed for slabs

339 with equivalent thickness, possibly demonstrating poor homogeneity of the thermal

340 exposures for slabs tested simultaneously during a single furnace test; this is despite the

341 temperatures measured by the plate thermometers complying with the test standard. Figure 13

342 suggests a more rapid through-thickness temperature increase for $45 \mathrm{~mm}$ thick slabs

343 positioned near the centre of the furnace, slabs \#2 and \#4, relative to Slab \#1 positioned near

344 the edge of the furnace (see Figure 7). A similar, however less severe, comparison is shown

345 in Figure 14 for Slab \#3, positioned at the centre of the furnace, and Slab \#5, positioned near 346 the edge of the furnace. 

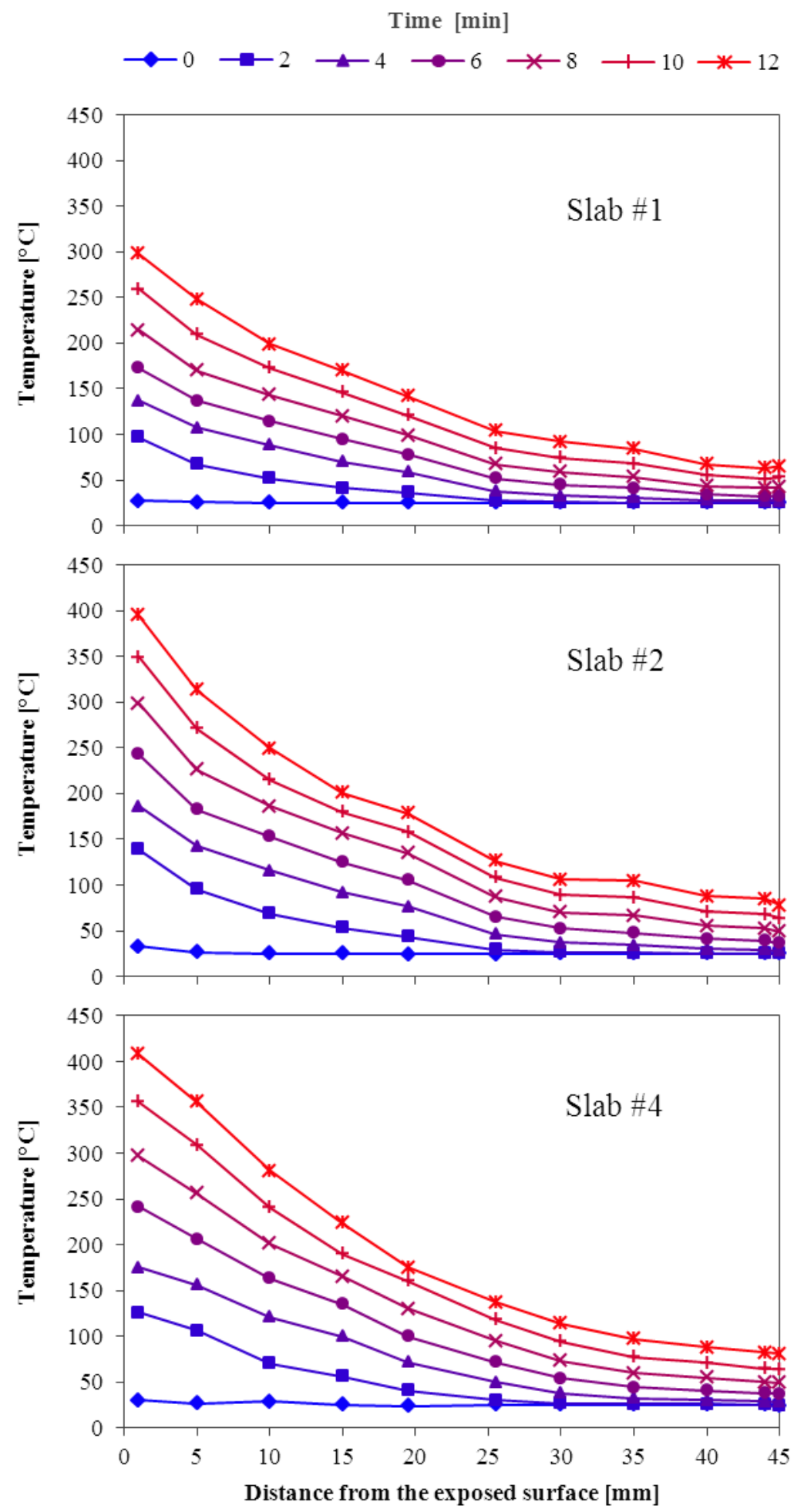


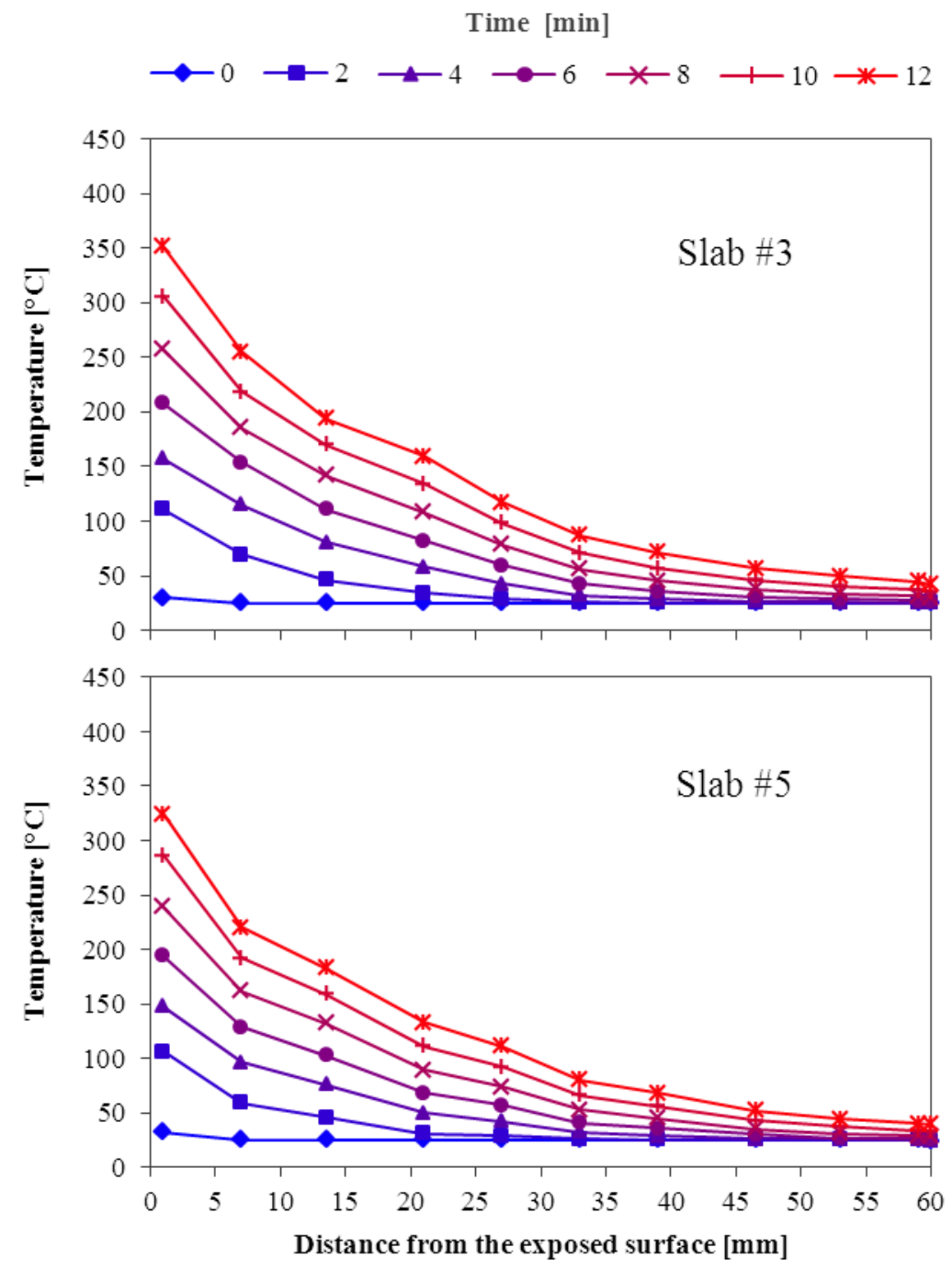

Figure 14 - Midspan through-thickness temperature distributions for $60 \mathrm{~mm}$ thick slabs at 2 minute intervals during the first 12 minutes of the furnace test.

\subsection{Temperature in the anchorage zone}

355 Figure 15 shows a comparison of the temperature of the CFRP tendon at midspan and at 400 $356 \mathrm{~mm}$ from the end of the slab (still within the heat exposed zone of the slab, see Figure 2) for

357 slabs \#1, \#4, and \#5 (all of which failed due to loss of anchorage). Figure 15 suggests that the 358 temperature of the CFRP tendons was essentially constant over the exposed length of the slabs. It is noteworthy that thermocouples were placed along the lower edge of an interior

360 CFRP tendon, and therefore recorded the temperature at the interface between the tendon and 361 the concrete, rather than the temperature of the CFRP itself. Due to the low thermal inertia of 
362 the CFRP tendons relative to that of concrete, the temperature inside the tendon may be lower

363 than that at the tendon-concrete interface in the fire exposed zone (e.g. at midspan); while the

364 opposite may be true in the unheated overhangs.

365 Figure 16 shows a comparison of the temperatures measured in the anchorage zone for Slab

$366 \# 5$, demonstrating the effectiveness of maintaining a 'cool' anchorage zone when designing

367 for unheated overhangs.

368 Within the scope of the work presented herein, no attempt was made to individually identify

369 the relevance of the two potential mechanisms for loss of anchorage: thermo-mechanical

370 bond degradation in the anchorage zone and/or thermo-mechanically induced longitudinal

371 splitting cracking. Further work is needed to better understand the drivers for, and

372 consequences of, both mechanisms.

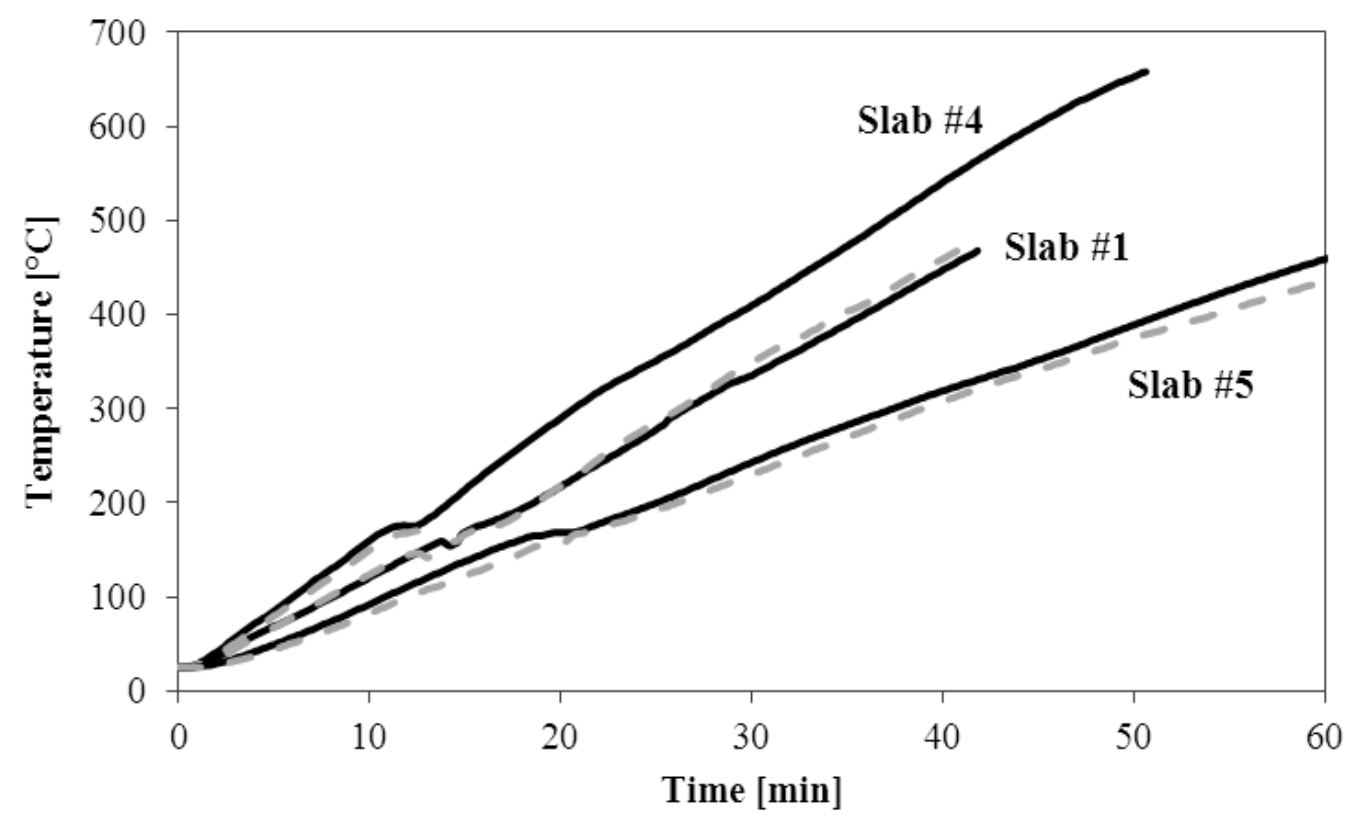

374 Figure 15 - Comparison between temperatures of the CFRP tendons measured at midspan (continuous

375 line) and at $\mathbf{4 0 0} \mathbf{~ m m}$ from the end of the slab (segmented line) for slabs \#1, \#4, and \#5. 


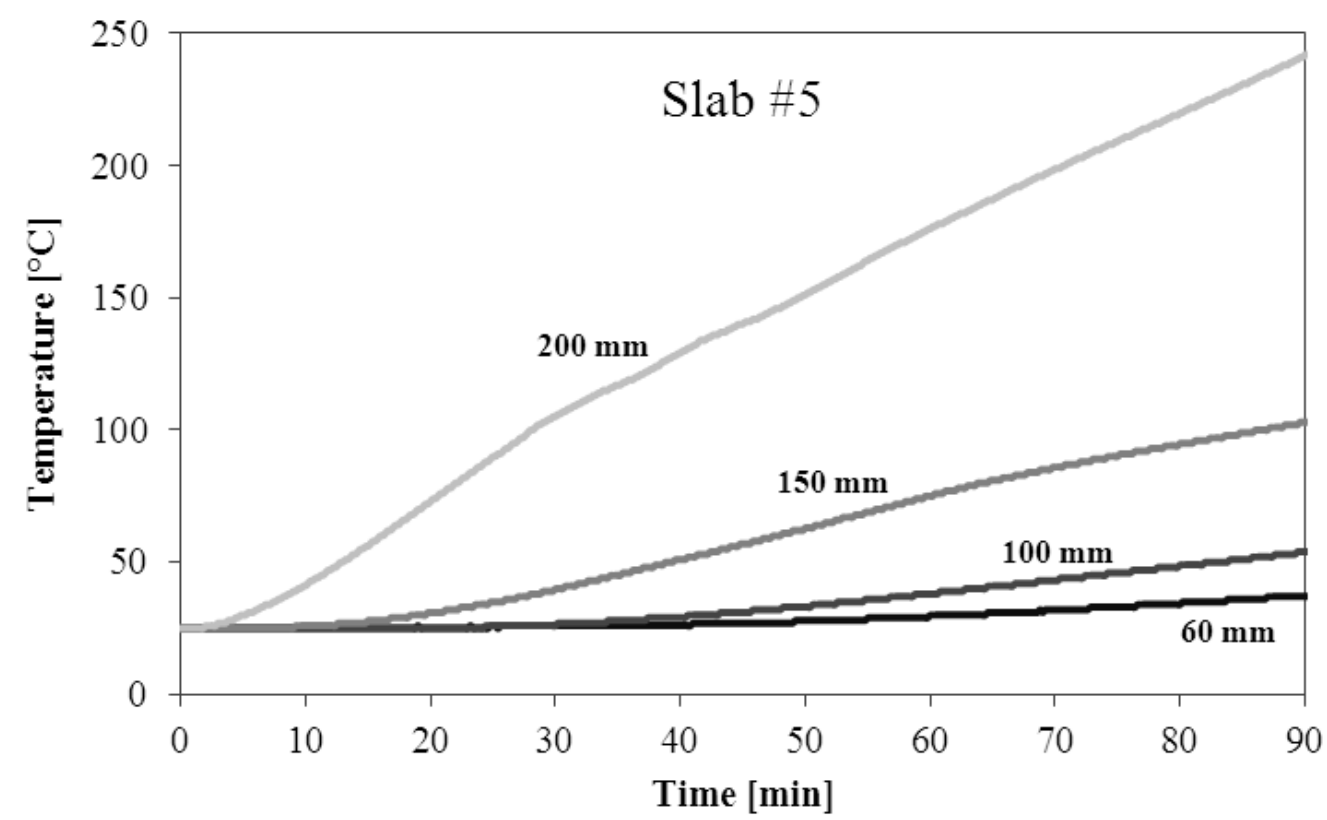

Time $[\mathrm{min}]$

Figure 16 - Typical temperature within the unheated overhang for a central CFRP tendon (Slab \#5, 60 mm thick), for distances of $60,100,150$, and $200 \mathrm{~mm}$ from the end of the slab.

\subsection{Midspan vertical displacement}

380 Figure 17 shows the time-history of midspan vertical displacements for the slabs that failed 381 due to loss of anchorage. During the early stages of the test, midspan deflections were 382 induced predominantly by thermal bowing. During this stage an obvious influence of the 383 slabs' thickness was observed [37]; wherein thicker slabs experienced less vertical midspan 384 deflection due to lower thermally induced curvatures. Comparison of midspan deflections for 385 slabs \#1 and \#4 (both $45 \mathrm{~mm}$ thick), during the first 10 minutes of the tests, shows that the more rapid increases of through-thickness temperature (observed for slab \#4, refer to Figure

387 13) resulted in a more rapid increase in midspan deflection due to thermal bowing (see Figure

388 17). For slabs \#1, \#4, and \#5, all of which failed due to loss of anchorage, a clear change of 389 slope in the time-history of midspan deflections, presumed to be associated with loss of anchorage, was observed (discussed later). 


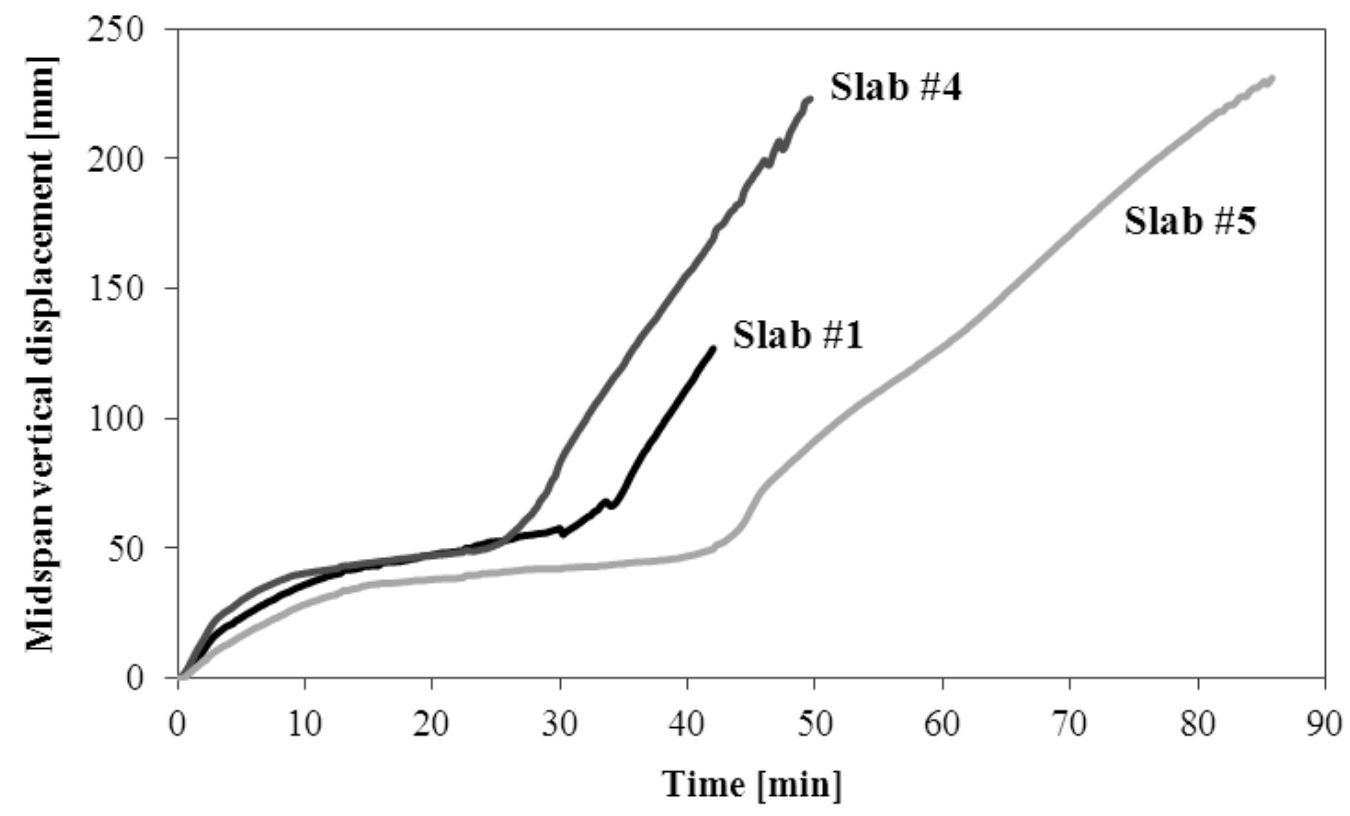

Time [min]

392 Figure 17 - Time-history of midspan vertical displacement measurements for all slabs that failed due to loss of anchorage (slabs \#1, \#4, and \#5).

\section{$394 \quad 5.5 \quad$ Draw-in of CFRP tendons}

395 Draw-in measurements were taken for all four CFRP tendons at both ends of slabs \#1, \#2, and \#3. Unfortunately, because slabs \#2 and \#3 failed catastrophically at an early stage of the

397 test due to explosive concrete spalling, no useful draw-in measurements were recorded for

398 these slabs. For Slab \#1 however, tendon draw-in measurements were taken until failure, at

39942 minutes from the start of the test as shown in Figure 18. While no attempt was made to

400 quantify the relationship between draw-in measurements and the failure mechanism of Slab

$401 \quad \# 1$, a qualitative analysis considering draw-in measurements, loss of anchorage, and failure is 402 presented later. 


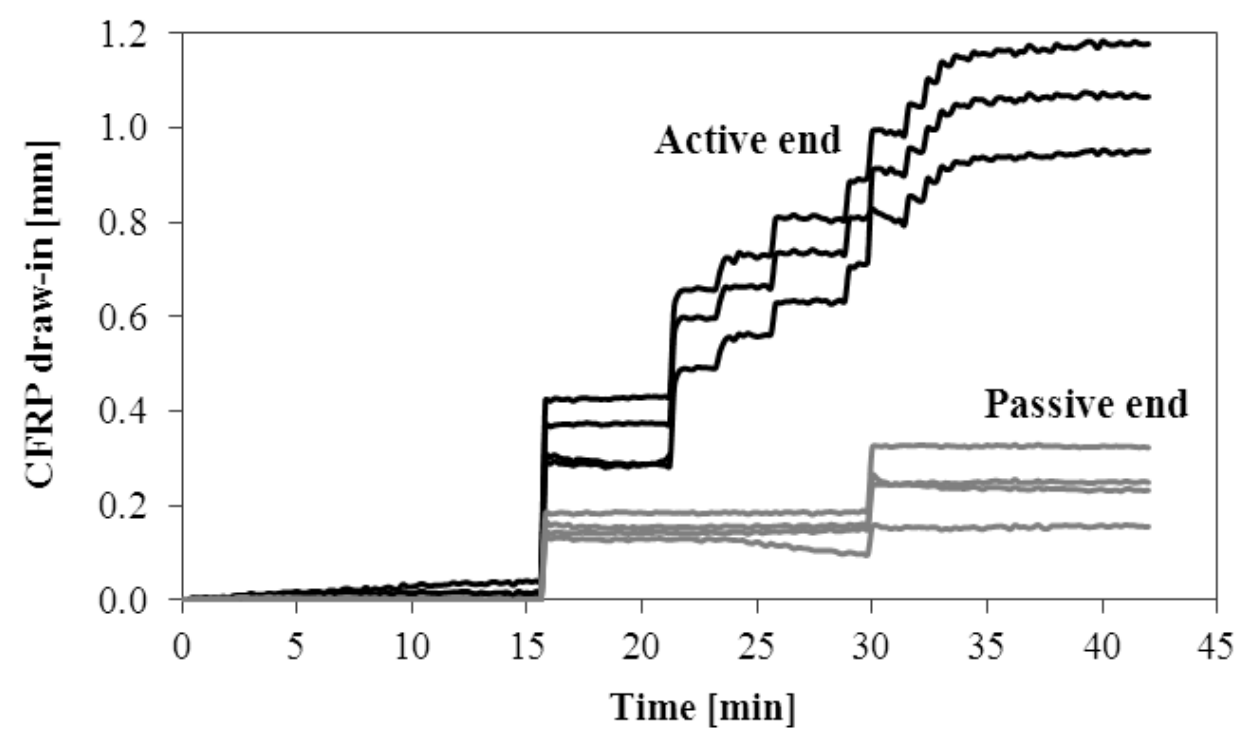

403

404 Figure 18 - Draw-in measurements for tendons at the active and passive ends of Slab \#1 during testing.

4056 ANALYSIS AND DISCUSSION

406

\subsection{Failure due to spalling}

407 Failure of slabs \#2 and \#3 was driven by the occurrence of single explosive concrete spalling 408 events, 12 and 22 minutes from the start of the test, respectively (refer to Table 1). 409 Immediately after spalling, each of these slabs suffered catastrophic failure and collapsed into 410 the furnace. Video stills recorded during testing showed the moment at which spalling 411 occurred (shown for Slab \#2 in Figure 19).

412 Slab \#2 failed after 12 minutes, whereas the virtually identical Slab \#1 failed due to loss of

413 anchorage after 42 minutes of fire exposure (refer to Table 1); Figure 13 shows that Slab \#2

414 experienced more rapid heating during the early stages of the test. This suggests a possible

415 important influence of the time-history of through-thickness temperatures on the occurrence

416 of heat-induced concrete spalling [11]. For instance, Slab \#2 spalled when the measured

417 temperature $1 \mathrm{~mm}$ from its exposed surface was $400^{\circ} \mathrm{C}$, while for Slab \#1 the temperature at 418 the same location was only $300^{\circ} \mathrm{C}$. The possibility that this was due to misplacement of 
419 thermocouples during casting was discarded since equivalent temperature differences 420 between slabs \#1 and \#2 were observed for temperatures measured at various positions in the 421 slab (e.g. 5, 10, and $15 \mathrm{~mm}$ from the exposed surface).

422 For slabs \#4 and \#5, both of which were cast from Mix B, no spalling was observed and thus 423 it is not possible to determine whether time-history of through-thickness temperatures might 424 influence the occurrence of spalling for this mix. The above demonstrates an inability to 425 properly compare test results for multiple specimens simultaneously tested during a single furnace test when subtle differences in thermal gradients play important roles in the test outcomes.

428

429

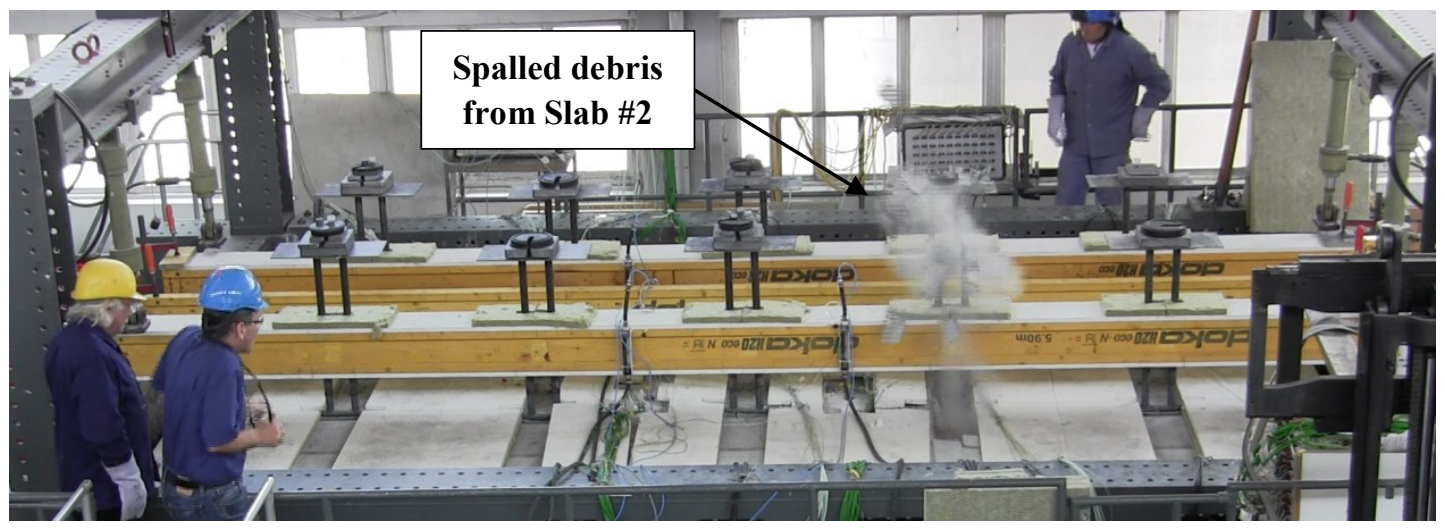

Figure 19 - Explosive spalling and immediate collapse of Slab \#2 at 12' 37'.

\subsection{Failure due to loss of anchorage}

The failure mechanism for slabs \#1, \#4, and \#5 was driven by loss anchorage of the CFRP tendons, which resulted in structural failure at 42, 50, or 93 minutes from the start of the test, respectively (refer to Table 1). As already noted, loss of anchorage for high-performance CFRP prestressed concrete structural elements during fire resistance tests has previously been postulated to be driven by a combination of thermo-mechanical bond degradation, thermomechanically induced longitudinal splitting cracks, or a combination of both mechanisms. 
437 Identifying (either experimentally or theoretically) the relative influences of these factors is nontrivial but is treated in this section using the data obtained from the tests presented herein.

Figure 17 shows the time-history of midspan deflections for slabs \#1, \#4, and \#5 all of which failed due loss of anchorage. While deflections at an early stage of the test were governed by thermal bowing of the test specimens, the observed increase in the rate of midspan deflection slope is thought to be linked to loss of anchorage (i.e. tendon slip).

Table 3 shows (for slabs \#1, \#4, and \#5) the time from the start of the test, the temperature of the CFRP tendons at midspan and $200 \mathrm{~mm}$ from the end of the slab for the following events:

- A clear increase in the rate of midspan vertical displacement was observed - This occurs when the temperature of CFRP tendons at midspan was about $310^{\circ} \mathrm{C}$ (refer to Table 3). The temperature of the CFRP tendons $200 \mathrm{~mm}$ from the end of the slab at this moment was about $70-78^{\circ} \mathrm{C}$ for the $45 \mathrm{~mm}$ thick slabs (slabs \#1 and \#4), and $124^{\circ} \mathrm{C}$ for the 60 mm thick slab (Slab \#5).

- The first longitudinal cracks were observed at the unexposed surface - This occurs when temperature of the CFRP tendons at midspan was between 320 and $390^{\circ} \mathrm{C}$ (refer to Figure 15), regardless of the temperature in the unheated overhangs (e.g. $200 \mathrm{~mm}$ from the end of the slab, refer to Figure 16). Longitudinal splitting cracks were first observed at the unexposed surface (i.e. top surface), near the midspan region (see Figure 20).

- Failure occurred (i.e. collapse) - The midspan temperature of the CFRP tendon at failure of the slabs was higher for slabs that incorporated CFRP grids within the anchorage zones. Slab \#1, which had no CFRP grids, failed when the temperature of the CFRP tendons at midspan was $459^{\circ} \mathrm{C}$, while slabs \#4 and \#5, both of which included CFRP grids, failed when the temperature of the CFRP tendons at midspan was $594^{\circ} \mathrm{C}$ 

45 and $60 \mathrm{~mm}$, respectively, their failure occurred when the temperature of the CFRP tendons at midspan was essentially the same.

463 The increase in midspan vertical displacement, appearance of the first longitudinal splitting 464 crack, and failure of the slabs were apparently unrelated to the temperature of the CFRP 465 tendons in the unheated overhangs.

Table 3 - Time from the start of the test, the temperature of the CFRP tendons at midspan and $200 \mathbf{m m}$ observed; (2) the first longitudinal crack was observed at the unexposed surface (i.e. the top surface); and (3) at failure for Slabs \#1, \#4, and \#5.

\begin{tabular}{|c|c|c|c|c|c|c|c|c|c|}
\hline \multirow[b]{2}{*}{ Slab \# } & \multicolumn{3}{|c|}{$\begin{array}{l}\text { Increase in the rate of midspan } \\
\text { vertical displacement }\end{array}$} & \multicolumn{3}{|c|}{ First longitudinal splitting crack } & \multicolumn{3}{|c|}{ Failure (i.e. structural collapse) } \\
\hline & $\begin{array}{c}\text { Time } \\
\text { [mm' ss"] }\end{array}$ & $\begin{array}{c}\text { Midspan } \\
{\left[{ }^{\circ} \mathbf{C}\right]}\end{array}$ & $\begin{array}{c}\begin{array}{c}\text { Unheated } \\
\text { overhang }\end{array} \\
{\left[{ }^{\circ} \mathrm{C}\right]}\end{array}$ & $\begin{array}{c}\text { Time } \\
\text { [mm' ss"] }\end{array}$ & $\begin{array}{c}\text { Midspan } \\
{\left[{ }^{\circ} \mathrm{C}\right]}\end{array}$ & $\begin{array}{c}\text { Unheated } \\
\text { overhang } \\
{\left[{ }^{\circ} \mathbf{C}\right]}\end{array}$ & $\begin{array}{c}\text { Time } \\
\text { [mm' ss"] }\end{array}$ & $\begin{array}{c}\text { Midspan } \\
{\left[{ }^{\circ} \mathbf{C}\right]}\end{array}$ & $\begin{array}{c}\text { Unheated } \\
\text { overhang } \\
{\left[{ }^{\circ} \mathrm{C}\right]}\end{array}$ \\
\hline 1 & $28^{\prime} 00^{\prime \prime}$ & $315^{\circ} \mathrm{C}$ & $70^{\circ} \mathrm{C}$ & $28^{\prime} 40^{\prime \prime}$ & $322^{\circ} \mathrm{C}$ & $72^{\circ} \mathrm{C}$ & $42^{\prime} 01^{\prime \prime}$ & $459^{\circ} \mathrm{C}$ & $102^{\circ} \mathrm{C}$ \\
\hline 4 & $21^{\prime} 24 "$ & $310^{\circ} \mathrm{C}$ & $78^{\circ} \mathrm{C}$ & $26^{\prime} 16^{\prime \prime}$ & $376^{\circ} \mathrm{C}$ & $94^{\circ} \mathrm{C}$ & $50^{\prime} 27^{\prime \prime}$ & $594^{\circ} \mathrm{C}$ & $165^{\circ} \mathrm{C}$ \\
\hline 5 & $38^{\prime} 00^{\prime \prime}$ & $309^{\circ} \mathrm{C}$ & $124^{\circ} \mathrm{C}$ & $50^{\prime} 40^{\prime \prime}$ & $390^{\circ} \mathrm{C}$ & $153^{\circ} \mathrm{C}$ & 93' 04" & $597^{\circ} \mathrm{C}$ & $246^{\circ} \mathrm{C}$ \\
\hline
\end{tabular}

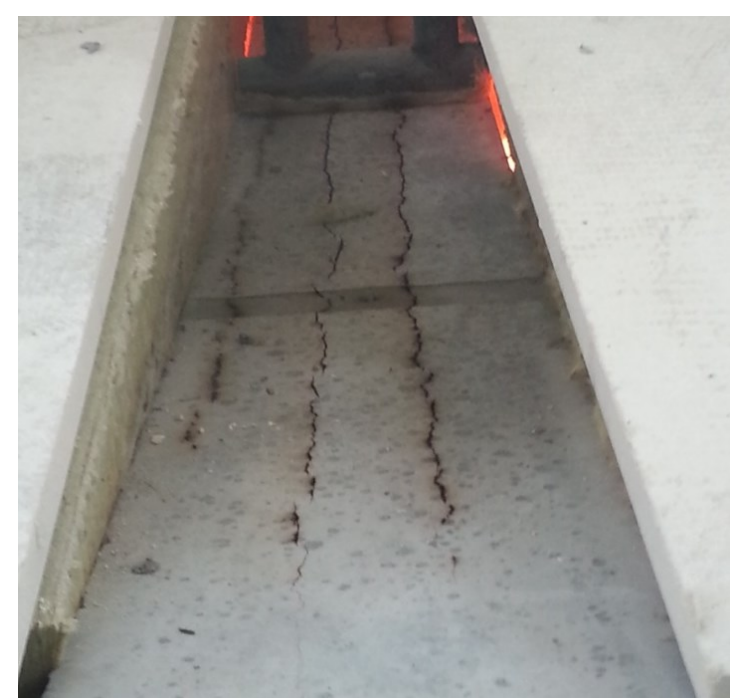


472 Figure 18 shows draw-in measurements for CFRP tendons in Slab \#1, evidencing that draw-

473 in initiated 16 minutes from the start of the test; at both the active and passive end of the slab.

474 Thereafter, draw-in progressively increased only at the active end up to 30 minutes from the 475 start of the start when a sudden increase in draw-in was measured at the passive end; around 476 the time at which an increase in the rate of midspan vertical displacement was observed for 477 Slab \#1 (refer to Figure 17).

478 Interestingly, the time-history of midspan vertical displacement directly correlates with the 479 temperature of the CFRP tendons at midspan (see Figure 21), rather than temperature in the 480 unheated overhangs. This physical mechanism is thought to be associated with heat-induced 481 reduction for strength and stiffness of the epoxy resin within CFRP tendons; since the epoxy 482 resin is essential for anchorage to be maintained [4], and moreover for preserving interaction 483 and stress transfer between individual carbon fibres. Thermogravimetric analysis performed 484 by the authors on these particular CFRP tendons showed that decomposition of the epoxy 485 resin rapidly initiates at around $290^{\circ} \mathrm{C}$ [4]; in accordance with the temperature of the CFRP 486 tendons at midspan for which an increase in midspan vertical displacement was observed 487 (refer to Figure 21). 


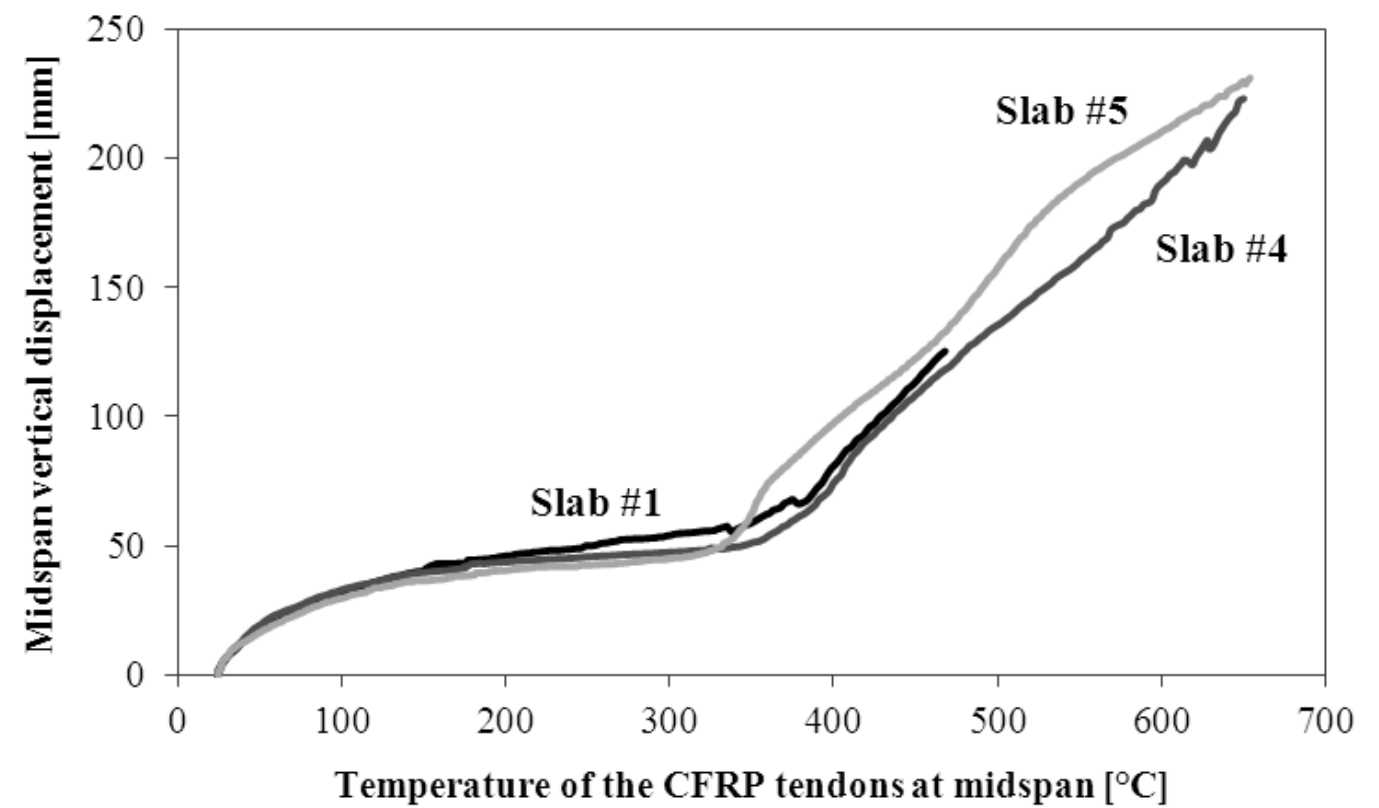

488

Temperature of the CFRP tendons at midspan $\left[{ }^{\circ} \mathrm{C}\right]$

Figure 21 - Variation of midspan vertical displacement with temperature of the CFRP at midspan.

\subsection{Influence of varying parameters}

491 The following observations can be made regarding the influences of the various parameters

492 investigated in the furnace test presented herein:

- Concrete mix - Mix B has a lower risk of heat-induced concrete spalling than Mix A, 494 despite the fact that Mix A incorporated a higher dose of $2.0 \mathrm{~kg}$ of PP fibres ( $3 \mathrm{~mm}$ long) 495 per $\mathrm{m}^{3}$ of concrete (as compared with $1.2 \mathrm{~kg}$ of $6 \mathrm{~mm}$ long PP fibres for Mix B). This 496 suggests that not only PP fibre dose, as prescribed by most design guidelines (e.g. [13]), 497 but also the length of the individual PP fibres has an influence on the effectiveness of PP 498 fibres effectiveness at mitigating spalling; the current (limited) study therefore supports 499 the use of $6 \mathrm{~mm}$ long fibres, although additional research is needed to corroborate this $500 \quad$ result.

- Overall slab thickness - The fire resistance of CFRP prestressed HPSCC slabs is directly associated to the overall slab thickness, with thicker slabs (unsurprisingly) having higher 
503 fire resistances. The above is only valid when the slabs' failure mechanism is driven by 504 loss of anchorage rather than heat-induced concrete spalling. The positive influence 505 given by the slab thickness (hence concrete cover to the reinforcement) is fundamental to 506 the fire safety of concrete structural elements reinforced with steel or FRP [38].

507 - The presence of CFRP grids within the anchorage zones - For the CFRP prestressed 508 HPSCC slabs that failed due to loss of anchorage rather than spalling, the presence of 509 CFRP grids within the anchorage zones appears to increase the anchorage resistance of 510 the prestressed CFRP tendons; hence the overall fire resistance of slabs.

\section{CONCLUSIONS}

512 Recognizing that it is challenging to draw categorical conclusions on the basis of a limited

513 number of large-scale tests on CFRP prestressed HPSCC slabs simultaneously tested during a

514 furnace test, the following conclusions can be drawn on the basis of the data and analysis 515 presented in this paper:

516 - The fire resistance of CFRP prestressed HPSCC slabs during a standard fire resistance 517 test is influenced by the occurrence of heat-induced concrete spalling, and if no spalling $518 \quad$ occurs, by loss of anchorage.

- Although all five test specimens were tested simultaneously and exposed to the same notional time-history of temperature inside the furnace, variability was observed in the

521 time-history of through-thickness temperatures for essentially identical slabs. This demonstrates the relatively poor, although 'test standard compliant', homogeneity of the thermal loading imposed during a standard furnace test [32]. Interestingly, more rapid

524 through-thickness temperature increases were measured for slabs at the centre of furnace, 525 relative to those near its walls. 
526 Relevant to the failure of slabs induced by the occurrence of heat-induced concrete spalling, 527 the following conclusions can be made:

528

529

- Failure of slabs \#2 and \#3 was driven by the occurrence of a single explosive spalling event leading to sudden failure.

- The occurrence of heat-induced concrete spalling appears to be subtly influenced by the time-history of through-thickness temperature within a concrete slab. Comparison of temperature measurements recorded for slabs \#1, \#2, and \#3 (all Mix A) indicated an influence of time-history of through-thickness temperatures on the occurrence of heatinduced concrete spalling. More rapid through-thickness temperature increases were measured for slabs \#2 and \#3, which spalled at 12 and 22 minutes, respectively.

- Results suggest that a lower risk of spalling exists for slabs cast with Mix B (containing $1.2 \mathrm{~kg} / \mathrm{m}^{3}$ of $6 \mathrm{~mm}$ long PP fibres) than for those cast with Mix A $\left(2.0 \mathrm{~kg} / \mathrm{m}^{3}\right.$ of $3 \mathrm{~mm}$ long PP fibres). This may be related to the short PP fibres ( $3 \mathrm{~mm}$ long) included in Mix A being less effective in mitigating heat-induced concrete spalling. It is noteworthy that existing European (and other) design guidelines for concrete in fire [13] prescribe the inclusion of $2 \mathrm{~kg} / \mathrm{m}^{3}$ of monofilament PP fibres to 'avoid' spalling; this is clearly indefensible based on the tests presented herein. Furthermore, these guidelines provide no guidance on the required PP fibre diameter or length.

Relevant to failure of slabs induced by loss of anchorage:

- Whilst no attempt was made to individually identify the influence of thermo-mechanical bond degradation versus thermo-mechanically induced longitudinal splitting cracking on the loss of anchorage in CFRP prestressed HPSCC slabs, the tests confirmed that a combination of both mechanisms is probably relevant. 
- Irrespective of all design parameters assessed in this study, loss of anchorage appeared to

550 begin when the temperature at the lower edge of a central CFRP tendon at midspan was

551 in the range of $310^{\circ} \mathrm{C}$, regardless of the temperature at the unheated overhangs. This

552 confirms the potential triviality of prescribing an unheated overhang length for the fire

553 resistance design of precast CFRP prestressed HPSCC slabs [10]. The precise reasons for

554 this remain unknown, although test results suggest influences of both longitudinal

555 thermal conduction (along and inside the CFRP tendons) and/or differential thermal

556 expansion (transverse to the tendon).

- The presence of CFRP grids within the anchorage zones appeared to increase the timeto-failure for slabs that failed due to loss of anchorage. Slabs \#4 and \#5, which incorporated CFRP grids, failed when the temperature at the bottom of the CFRP tendon at midspan was at about $600^{\circ} \mathrm{C}$, while it occurred at $450^{\circ} \mathrm{C}$ for Slab $\# 1$ which did not incorporate grids. Increase in fire resistance is thought to be associated with increased longitudinal splitting crack resistance and confining action provided by concrete (and CFRP grids) in the anchorage zones.

The current study reveals some of the inadequacies of using standard furnace tests for carefully investigating the fire resistance of CFRP prestressed HPSCC slabs (or similarly novel or highly optimized structural elements). The high risk of heat-induced concrete spalling and the complexities associated with loss of anchorage, both of which are relevant to the fire behaviour of CFRP prestressed HPSCC slabs, are difficult to be rationally investigated with a low number of test specimens, despite considerable instrumentation during testing. A proper understanding of the response of these elements is needed before they can be designed and implemented with confidence; this is unlikely to be achieved by performing additional standard fire resistance tests. Conversely, what is needed is scientific 
573 understanding of the thermal and mechanical fire behaviour of these elements at the material, 574 member, and system levels; this can be accomplished using a range of conventional and 575 bespoke test methods and procedures, many of which are now being used by the authors (e.g. $576[11])$.

\section{ACKNOWLEDGEMENTS}

578 The authors would like to thank SACAC Schleuderbetonwerk AG, Empa, and The University 579 of Edinburgh, and in particular Lukas Bäurle, Nunzio Spano, Thomas Hofer, Marcel Steiner, 580 Angelo Demont, and Mauricio Fuentes. This research was partially funded by Empa, the

581 BRE Centre for Fire Safety Engineering at The University of Edinburgh, and The Royal 582 Society of Edinburgh. Arup and the Royal Academy of Engineering are gratefully 583 acknowledged for their ongoing support of Arup Prof Bisby.

\section{NOTATION}

$585 \quad A_{c} \quad$ concrete cross section area

$586 \quad A_{\text {CFRP }} \quad$ CFRP tendons cross section area

$587 \quad E_{c} \quad$ elastic modulus of concrete

$588 \quad E_{\text {CFRP }} \quad$ elastic modulus of CFRP tendons

$589 \quad \varepsilon_{c}^{S R} \quad$ concrete strains due to shrinkage

$590 \Delta \sigma_{p}^{\text {Total }} \quad$ total prestressing losses

$591 \Delta \sigma_{p}^{E S} \quad$ prestressing losses due to elastic shortening of concrete

$592 \Delta \sigma_{p}^{S R} \quad$ prestressing losses due to shrinkage of concrete

$593 \Delta \sigma_{p}^{C R} \quad$ prestressing losses due to creep of concrete

$594 \sigma_{c, \text { botom }}$ normal stress in concrete at the bottom fibre of slab

$595 \quad \sigma_{c, 0} \quad$ initial normal stress in concrete 
$596 \sigma_{C F P P, 0} \quad$ initial normal stress in CFRP tendons

$597 \sigma_{c, \text { rrepp }} \quad$ normal stress in concrete after creep

$598 \sigma_{\text {CFRP, lest }}$ initial prestressing level of the CFRP tendons during testing

$599 \varphi_{c} \quad$ concrete creep coefficient

$600 \varphi_{\text {CRRP }} \quad$ CFRP tendon-concrete bond creep coefficient

601 


\section{REFERENCES}

603 [1] Terrasi G.P. Prefabricated thin-walled structural elements made from HPC prestressed

[3] Seica M.V. and Packer J.A. FRP Materials for the Rehabilitation of Tubular Steel

[2] Terrasi G.P., Battig G., and Bronnimann R. Pylons made of high-strength spun concrete and prestressed with carbon fibre reinforced plastic for high power transmission lines. International Journal of Materials and Product Technology, 2002, 17 (1-2), 32-45.

612 [4] Maluk C., Bisby L., Terrasi G.P., Hugi E., and Green M. Bond strength degradation for 613 CFRP and steel reinforcing bars in concrete at elevated temperature. American 614 Concrete Institute Special Publication on Advances in Fire Design of Concrete Structures (ACI SP-297), 2011, 36 pp.

616 [5] Kodur V.K.R. and Baingo D. Fire Resistance of FRP reinforced concrete slabs. Institute for Research in Construction (internal report), 1998, 44 pp.

618 [6] Kodur V.K.R. and Bisby L.A. Evaluation of Fire Endurance of Concrete Slabs 619 Reinforced with Fiber-Reinforced Polymer Bars. Journal of Structural Engineering, 620 2005, $131(1), 34-43$. 
621 [7] Abbasi A. and Hogg P.J. Fire Testing of Concrete Beams with Fibre Reinforced Plastic Rebar. Composites Part A: Applied Science and Manufacturing, 2006, 37 (8), 11421150.

[8] Nigro E, Cefarelli G., Bilotta A., Manfredi G., and Cosenza E. Fire resistance of 625 concrete slabs reinforced with FRP bars. Part I: Experimental investigations on the mechanical behavior. Composites Part B: Engineering, 2011, 42 (6), 1739-1750.

[9] Rafi M.M. and Nadjai A. Fire Tests of Hybrid and Carbon Fiber-Reinforced Polymer Bar Reinforced Concrete Beams. ACI Materials Journal, 2011, 108 (3), 252-260.

[10] Terrasi G.P., Bisby L., Barbezat M., Affolter C., and Hugi, E. Fire Behavior of Thin 630 CFRP Pretensioned High-Strength Concrete Slabs. Journal of Composites for Construction, 2012, 16 (4), 381-394.

[11] Maluk C. Development and Application of a Novel Test method for Studying the Fire Behaviour of CFRP Prestressed Concrete Structural Elements. Ph.D Thesis, The University of Edinburgh, UK, 2014, 473 pp.

[12] Bailey C.G. and Khoury G.A. Performance of Concrete Structures in Fire - An Indepth Publication on the Behaviour of Concrete in Fire. MPA - The Concrete Centre, Ruscombe Printing Ltd, Reading, UK, 2011, 187 pp.

[13] CEN. Eurocode 2: Design of Concrete Structures - Parts 1-2: General Rules 639 Structural Fire Design (EN 1992-1-2). European Committee for Standardization, Brussels, 2004, 100 pp.

[14] CCAA. Fire Safety of Concrete Buildings. Cement Concrete \& Aggregates Australia (CCAA), 2013, 33 pp. 
643 [15] Katz A. and Berman N. Modeling the Effect of High Temperature on the Bond of FRP

644 Reinforcing Bars to Concrete. Cement and Concrete Composites, 2000, 22 (6) 433-443.

645 [16] Bisby L.A. and Kodur V.K.R. Evaluating the Fire Endurance of Concrete Slabs 646 Reinforced with FRP Bars: Considerations for a Holistic Approach. Composites Part B: $647 \quad$ Engineering, 2007, 38 (5-6), 547-558.

648 [17] Katz A. Bond Mechanism of FRP Rebars to Concrete. Materials and Structures, 1999, $649 \quad 32(10), 761-768$.

650 [18] Morley P.D. and Royles R. The Influence of High Temperature on the Bond in 651 Reinforced Concrete. Fire Safety Journal, 1980, 2 (4), 243-255.

652

[19] Bednarek Z. and Ogrodnik P. Testing steel-concrete bond in fire conditions. Proceedings of the $9^{\text {th }}$ International Conference Modern Building Materials, Structures

[20] Haddad R.H., Al-Saleh R.J., and Al-Akhras N.M. Effect of Elevated Temperature on 656 657 and Techniques, Vilnius, Lithuania, 2007, 1152-1158.

[21] Pothisiri T. and Panedpojaman P. Modeling of Mechanical Bond-Slip for Steel659 Reinforced Concrete Under Thermal Loads. Engineering Structures, 2013, 48 (March), 660 497-507.

661

[22] Aiello M.A., Leone M., and Pecce M. Bond Performances of FRP Rebars-Reinforced 662 Concrete. Journal of Materials in Civil Engineering, 2007, 19 (3), 205-213. 
663 [23] Wang Y.C., Wong P.M.H., and Kodur V.K.R. An Experimental Study of the Mechanical Properties of Fibre Reinforced Polymer (FRP) and Steel Reinforcing Bars at Elevated Temperatures. Composite Structures, 2007, 80 (1), 131-140.

666

667

668

669

670

671

672

673

674

675

676

677

678

679

680

681

682

683

684

[24] ACI. Prestressing Concrete Structures with FRP Tendons (ACI 440.4R-04). American Concrete Institute, Farmington Hills, MI, US, 2004, 35 pp.

[25] FIB. FRP Reinforcement for RC Structures. Technical report prepared by Task Group 9.3 FRP (Fibre Reinforced Polymer) reinforcement for concrete structures. Lausanne, Switzerland, 2006, 157 pp.

[26] CNR. Guide for the Design and Construction of Concrete Structures Reinforced with Fiber-reinforced Polymer Bars (CNR-DT 203/2006). National Research Council, Rome, Italy, 2007, 39 pp.

[27] Maluk C., Bisby L., and Terrasi G.P. High temperature compatibility of CFRP versus steel reinforcement for concrete. American Concrete Institute Special Publication Towards Sustainable Infrastructure with Fiber Reinforced Polymer Composites (ACI SP-440), 2015. (in press)

[28] Aiello M.A. Concrete Cover Failure in FRP Reinforced Beams under Thermal Loading. Journal of Composites for Construction, 1999, 3 (1), 46-52.

[29] Aiello M.A., Focacci F., and Nanni A. Effects of Thermal Loads on Concrete Cover of Fibre-Reinforced Polymer Reinforced Elements: Theoretical and Experimental Analysis. ACI Materials Journal, 2001, 98 (4), 332-339.

[30] Masmouid R., Zaidi A., and Gérard P. Transverse Thermal Expansion of FRP Bars Embedded in Concrete. Journal of Composites for Construction, 2005, 9 (5), 377-387. 
685 [31] Abdalla H. Concrete Cover Requirements for FRP Reinforced Members in Hot Climates. Composite Structures, 2006, 73 (1), 61-69.

687

688

689

690

691

692

693

694

695

696

697

698

699

700

701

702

703

704

705

[32] CEN. Eurocode: Fire Resistance Tests - Part 1: General Requirements (EN 13631:2012). European Committee for Standardization, Brussels, 2012, 56 pp.

[33] CEN. Eurocode: Testing Hardened Concrete - Part 6: Tensile Splitting Strength of Test Specimen (EN 12390-6:2009). European Committee for Standardization, Brussels, 2009, 14 pp.

[34] CEN. Eurocode: Testing Fresh Concrete - Part 8: Self-compacting Concrete - SlumpFlow Test (EN 12350-8:2010). European Committee for Standardization, Brussels, 2010, 14 pp.

[35] Terrasi G.P., Affolter C., and Barbezat M. Numerical Optimization of a Compact and Reusable Pre-tensioning Anchorage System for CFRP Tendons. Journal of Composites for Construction, 2010, 15 (2), 126-135.

[36] Empa. Concrete Shrinkage and Creep Strain Measurements (Bestimmung des Schwindund Kriechwertes). Internal report from the Swiss Federal Laboratories for Materials Science and Technology (Empa), Dübendorf, Switzerland, 2008, 4 pp.

[37] Usmani A.F., Rotter J.M., Lamont S., Sanad A.M., and Gillie M. Fundamental Principles of Structural Behaviour Under Thermal Effects. Fire Safety Journal, 2001, $36(8), 721-744$.

[38] Buchanan A.H. Structural Design for Fire Safety. John Wiley \& Sons Ltd., West Sussex, UK, 2001, 448 pp. 